\title{
A COMPARISON OF THE WIND SYSTEM ATMOSPHERIC MODELS AND RASCAL (U)
}

by

J. D. Fast

Westinghouse Savannah River Company

Savannah River Site

Aiken, South Carolina 29808

This report was prepared in connection with work done under Contract No. DE AC09-89SR 18035 with the U.S. Department of Energy. By acceptance of this report, the publisher and/or recipient acknowledges the U.S. Government's right to retain a nonexclusive, royalty-free license in and to any copyright covering this report, along with the right to reproduce and to authorize others to reproduce all or part of the copyrighted report. 


\section{DISCLAIMER}

This report was prepared as an account of work sponsored by an agency of the United States Government. Neither the United States Government nor any agency thereof, nor any of their employees, makes any warranty, express or implied, or assumes any leyal liability or responsibility for the accuracy, completeness, or usefuiness of any information, apparatus, product, or process disclosed, or represents that its use would not infringe privately owned rights. Reference herein to any specific commercial product, process, or service by trade name, trademark, manufacturer, or otherwise does not necessarily constitute or imply its endorsement, recommendation, or favoring by the United States Government or any agency thereof. The views and opinions of authors expressed herein do not necessarily state or reflect those of the United States Government or any agency thereof.

This report has been reproduced directly from the best available copy.

Available to DOE and DOE contractors from the Office of Scientific and Technical Information, P.O. Box 62, Oak Ridge, TN 37831; prices availabie from (615) 576-8401, FTS 626-8401.

Available to the public from the National Technical Information Service, U.S. Department of Commerce, 5285 Port Royal Rd., Springfield, VA 22161. 
WSRC-RP-91-894

\section{A COMPARISON OF THE WIND SYSTEM ATMOSPHERIC MODELS AND RASCAL (U)}

J. D. FAST

Publication Date: September 6, 1991

Westinghouse Savannah River Company Savannah River Site. Aiken, SC 29808 


\section{CONTENTS}

ABSTRACT

1.0 INTRODUCTION 1

2.0 DESCRIPTION OF THE MODELS 2

2.1 WIND System Atmospheric Codes 2

2.2 RASCAL Code 3

1.3 Comparison of the WIND System Codes and RASCAL 4

3.0 COMPARISON OF THE NUMERICAL RESULTS 5

3.1 AREA EVACUATION and RASCAL 6

3.2. PUFF/PLUME and RASCAL 7

3.3 2DPUF and RASCAL 7

3.4 WIND System Atmospheric Models and RASCAL 8

$\begin{array}{lll}4.0 & \text { DISCUSSION } & 8\end{array}$

5.0 CONCLUSION 9

REFERENCES 


\section{LIST OF FIGURES}

1. Inhalation dose calculated by AREA EVACUATION and RASCAL for a $60 \mathrm{~min}$ release with various wind speeds (cases $1,2,3$ from Table 5)

2. Inhalation dose calculated by AREA EVACUATION and RASCAL for a 60 min release with various atmospheric stabilities (cases 1 , 4, 5 from Table 5)

3. Inhalation dose calculated by AREA EVACUATION and RASCAL for a 60 min release with various boundary-layer depths (cases 1, 4, 6 from Table 5)

4. Inhalation dose calculated by AREA EVACUATION and RASCAL for a 60 min release with two isotopes (cases 1,8 from Table 5)

5. Inhalation dose calculated by PUFF/PLUME and RASCAL for a $60 \mathrm{~min}$ release with various wind speeds (cases $1,2,3$ from Table 5)

6. Inhalation dose calculated by PUFF/PLUME and RASCAL for a 60 min release with various atmospheric stabilities and a wind speed of $1 \mathrm{~m} \mathrm{~s}^{-1}$ (cases, 2, 9, 10 from Table 5)

7. Inhalation dose calculated by PUFF/PLUME and RASCAL for a 60 min release with various atmospheric stabilities (cases 1, 4, 5 from Table 5)

8. Inhalation dose calculated by PUFF/PLUME and RASCAL for a $60 \mathrm{~min}$ release with various boundary-layer depths (cases $1,4,6$ from Table 5)

9. Inhalation dose calculated by PUFF/PLUME and RASCAL for a 60 min release with two isotopes (cases 1, 8 from Table 5)

10. Inhalation dose calculated by PUFF/PLUME and RASCAL for 60 min release with various dry and wet deposition rates (cases 1 , $11,12,13,14$ from Table 5)

11. Inhalation dose calculated by PUFF/PLUME and RASCAL for a 15 min release with various wind speeds (cases $1,2,3$ from Table 5)

12. Inhalation dose calculated by PUFF/PLUME and RASCAL for a $15 \mathrm{~min}$ release with various atmospheric stabilities and a wind speed $1 \mathrm{~m} \mathrm{~s}^{-1}$ (cases 2, 9, 10 from Table 5)

13. Inhalation dose calculated by PUFF/PLUME and RASCAL for a 15 min release with various atmospheric stabilities (cases $1,4,5$ from Table 5) 
14. Inhalation dose calculated by PUFF/PLUME and RASCAL for a 15 min release with various boundary-layer depths (cases 1, 4, 6 from Table 5)

15. Inhalation dose calculated by PUFF/PL,UME and RASCAL for a $15 \mathrm{~min}$ release with two isotopes (cases 1,8 from Table 5)

16. Inhalation dose calculated by PUFF/PLUME and RASCAL for a 15 in release with various dry and wet deposition rates (cases 1 , $11,12,13,14$ from Table 5)

17. Inhalation dose calculated by 2DPUF and RASCAL for a $15 \mathrm{~min}$ release with various wind speeds (cases $1,2,3$ from Table 5)

18. Inhalation dose calculated by $2 D P U F$ and RASCAL for a $15 \mathrm{~min}$ release with various atmospheric stabilities (cases $1,4,5$ from Table 5)

19. Inhalation dose calculated by 2DPUF and RASCAL for a $15 \mathrm{~min}$ release with various boundary-layer depths (cases 1, 4, 6, 7 from Table 5)

20. Inhalation dose calculated by 2DPUF and RASCAL for a $15 \mathrm{~min}$ release with two isotopes (cases 1,8 from Table 5)

21. Cloud shine dose calculated by 2DPUF and RASCAL for a $15 \mathrm{~min}$ release with various wind speeds (cases $1,2,3$ from Table 5)

22. Cloud shine dose calculated by 2DPUF and RASCAL for a $15 \mathrm{~min}$ release with various atmospheric stabilities (cases 1, 4, 5 from Table 5)

23. Cloud shine dose calculated by 2DPUF and RASCAL for a $15 \mathrm{~min}$ release with various boundary-layer depths (cases $1,4,6,7$ from Table 5)

24. Clond shine dose calculated by 2DPUF and RASCAL for a $15 \mathrm{~min}$ release with various isotopes (cases 1, 8 from Table 5) 


\section{LIST OF TABLES}

1. Comparison of the source term capabilitites of the WIND System atmospheric models and RASCAL

2. Comparison of the atmospheric transport and diffusion capabilities of the WIND System atmospheric models and RASCAL

3. Comparison of the dose and consequence capabilities of the WIND System atmospheric models and RASCAL

4. Comparison of the operational characteristics of the WIND System atmospheric models and RASCAL

5. Input parameters for the WIND System atmospheric models and RASCAL

6. Cases that were employed by each of the WIND System atmospheric models and RASCAL

7. Comparison of the dose values predicted by RASCAL to the results of the WIND System atmospheric models at selected downwind distances

8. Comparison of the dose values predicied by RASCAL to the results of the individual WIND System atmospheric models

9. Ground centerline inhalation and cloud shine dose at selected downwind distances predicted by RASCAL using the input parameters specified in Table 5

10. Ground centerline inhalation dose at selected downwind distances predicted by AREA EVACUATION using the input parameters specified in Table 5

11. Ground centerline inhalation dose at selected downwind distances predicted by PUFF/PLUME using the input parameters specified in Table 5

12. Ground centerline inhalation and cloud shirie dose at selected downwind distances predicted by 2DPUF using the input parameters specified in Table 5 


\title{
A COMPARISON OF THE WIND SYSTEM ATMOSPHERIC MODELS AND RASCAL
}

\author{
By J. D. Fast \\ Westinghouse Savannah River Company \\ Savannah River Site \\ Aiken, SC 29808
}

\begin{abstract}
A detailed comparison of the characteristics of the WIND System atmospheric models and the NRC's RASCAI code was made. The modeling systems differ substantially in the way input is entered and the way output is displayed. Nevertheless, using the same source term and meteorological input parameters, the WIND System atmospheric models and RASCAL produce similar results in most situations. The WIND System atmospheric model predictions and those made by RASCAL are within a factor of two at least $70 \%$ of the time and are within a factor of four $89 \%$ of the time. Significant differences in the dose between the models may occur during conditions of low wind speeds, strong atmospheric stability, and/or wet deposition as well as for many atmospheric cases involving cloud shine. Even though the numerical results are similar in most cases, there are many site-specific and operational characteristics that have been incorporated into the WIND System atmospheric models to provide SRS emergency response personnel with a more effective emergency response tool than is currently available from using RASCAL.
\end{abstract}

\subsection{INTRODUCTION}

Atmospheric transport and diffusion models have been developed by the Environmental Technology Section (ETS) of Savannah River Laboratory to calculate the location and concentration of toxic or radioactive materials during an accidental release at the Savannah River Site (SRS). The results of these models have been used to support activities of the SRS emergency response organization, such as protective action decision making and field monitoring cciordination. These atmospheric transport and diffusion models have been incorporated intc, an automated computer-based system called the WIND (Weather INformation and Display) System. The WIND System is linked to real-time meteorological and radiological monitoring instruments to provide timely information for performing model calculations during emergency response activities.

In an effort to establish more formal quality assurance procedures for the WIND System atmospheric codes, a software evaluation is being conducted by the ETS 1 . This evaluation will determine the performance of these models in simulating the transport and diffusion of radionuclides or toxic materials. One of the objectives of the software evaluation is to compare the formulation of the models and the results they produce with other dispersion models: therefore, a comparison was performed between the WIND System atmospheric models and the Radiological Assessment System for Consequence and AnaLysis (RASCAL) code. RASCAL, developed for the U. S. Nuclear Regulatory Commission (NRC) by Oak Ridge National Laboratory (ORNL), was chosen for this comparison because it is used by federal and state agencies and commercial nuclear power sites in the United States. It also has many characteristics that are similar to the WIND System atmospheric codes. Since the WIND 
System atmospheric models and RASCAL are not exactly the same, it is important to be aware of the features employed by these models and how they affect the modeling of transport and diffusion of radioactive materials.

This report consists of two parts, each designed to provide the user with information about the models that are important in emergency response situations. The two parts are:

(1) Description of the Models: First, a brief description of all the models examined in this study is presented. Then, a detailed comparison of the characteristics of the WIND System atmospheric nodels and RASCAL is made. This comparison will include source term, atmospheric transport and diffusion, and dose and consequence assumptions as well as the operational characteristics of each of the models. Other documentation on the formulation of the models is referenced.

Comparison of the Numerical Results: Both the WIND System atmosnteric models and RASCAL were executed with the same source strength and meteorological data. The dose estimates produced by the models are compared and evaluated.

In addition, the applicability of the WIND System atmospheric models and RASCAL to the prediction of accidental radiological releases at the SRS will be discussed.

The atmospheric models in the WIND System have been compared with other published models as well. Data from the Mesoscale Atmospheric Transport Studies (MATS) tracer experiment at SRS ${ }^{2}$ was employed to evaluate a variety of dispersion models ${ }^{3.4}$. These models ranged in complexity from simple straight-line Gaussian, to three-dimensional, mass-consistent models. The performance of some of the WIND System atmospheric models in predicting the observed tracer distribution in the MATS experiments also has been examined 5 . This study represents the first detailed comparison of the WIND System atmospheric codes, in their present form, with other similar models.

\subsection{DESCRIPTION OF THE MODELS}

\subsection{WIND System Atmospheric Codes}

The atmospheric models of the WIND System to be used in the comparison include AREA EVACUATION, PUFF/PLUME, 2DPUF, and REACTOR ACCIDENT. These models vary in complexity because each was designed for a difference emergency response application. These codes currently run on a VAX 8550 mainframe computer so that they can easily access real-time meteorological and radiological monitoring data across the SRS. A number of remote terminals at various sites at the SRS can access these codes from the WIND System menu. The AREA EVACUATION, PUFF/PLUME, and 2DPUF codes are line-prompt systems, and the REACTOR ACCIDENT code is a menu-driven system.

\section{AREA EVACUATION Code}

The AREA EVACUATION $\operatorname{code}^{6}$ (version 2.0) is a simple, straight-line Gaussian model designed to calculate the movement of radionuclides close to the SRS production facility areas. This model is required to execute quickly since the results are needed for immediate protective action decisions within an affected area. Quality-assured observations from the SRS meteorological tower adjacent to the release location are used to calculate the plume direction, plume width, and dose estimates in the immediate vicinity of the release. The wind field does not vary in space or in time. Dose estimates are graphically depicted as contours overlaid on a background map. 


\section{PUFF/PLUME Code}

The 1PUFF/PLUME code 6,7 (yersion 2.5) is a segmented, straight-line Gaussian model designed to calculate plume characteristics to the site boundary and beyond during the early phase of an emergency due to a release at the site. PUFF/PLUME is more appropriate for relatively short releases because of the meteorological data that is employed. The code has four options for wind field based on quality-assured observations from SRS meteorological towers and forecasts from the NWS; however, in each case the wind field may vary in time but not in space. For instance, one option uses the most recent wind data at the release site and allows it to vary in time according to a Model Output Statistics (MOS) forecast. MOS forecasts employ regression equations to link the observed tower data with predictions from the National Weather Service (NWS) Limited Fine Mesh (LFM) model. A single 15 min release duration is used for "puff" calculations, or the user may specify the release duration for "plume" predictions. Dose or concentration estimates are determined for onsite and offsite locations. The dose or concentration estimates are automatically printed out in tabular form and graphically depicted as contours overlaid on a background map.

\section{DPUF Code}

The 2DPUF code 6,8 (version 3.1) is a sequential Gaussian model designed to calculate more complex concentration distributions on and off-site to obtain more accurate estimates of dose. 2DPUF can produce both "local" and "regional" forecasts because of the meteorological data that is employed. The code has four options for the wind field based on quality-assured observations from SRS meteorological towers and observations and forecasts from the NWS. The wind field may either vary in time but not in space for a "local" calculation, or may vary in space and in time for "regional" calculation. For instance, NWS hourly surface observations and available upper-air observations throughout the southeast can be used to generate a regional wind field that varies horizontally. NWS prediction models and MOS can also be used to calculate a time-dependent wind field that does not vary in space. The total duration of the release is specified by the user. The emission is then simulated as a series of "puffs", each with a 15 min duration. As in PUFF/PLUME, dose or concentration estimates are determined for onsite and offsite locations. Dose estimates are automatically printed out in tabular form and graphically depicted as contours overlaid on a background map.

The next version of 2DPUF will also include the deposition scheme and the dispersion parameters employed by PUFF/PLUME.

\section{REACTOR ACCIDENT Code}

The REACTOR ACCIDENT code 6 (version 3.2) provides near real-time estimates of plume characteristics and radiological dose due to an atmospheric release following a fuel damage incident at an SRS reactor facility. The code is used to support emergency response activities during, the early phase of a reactor area emergency, such as protective action decision making and field monitoring coordination. The model uses a segmented, straight-line Gaussian model that is nearly identical to PUFF/PLUME for the transpor: and diffusion of the radiological materials from the reactor area and calculates the value of the source term. Dose estimates are deternnined for onsite and offsite locations. The dose estimates are automatically printed out in tabular form or graphically depicted as contours overlaid on a background map.

\subsection{RASCAL Code}

The RASCAL (Radiological Assessment System for Consequence and AnaLysis) code 9 (version 1.3) was produced for the NRC by ORNL in 1989 as a federal emergency response 
tool. RASCAL is a menu-driven system that runs on IBM-compatible personal computers and was designed to assess the impact to man in the early phase of an accidental radiological release from a commercial nuclear power plant. It is a sequential Gaussian model that allows the wind field to vary in time, but not in space. Dose estimates may be printed out in tabular form and graphically depicted in ASCII characters.

\subsection{Comparison of the WIND System Atmospheric Codes and RASCAL}

A detailed comparison of the characteristics between the WIND System atmospheric codes and RASCAL has been made and is presented in Tables 1 - 4. These tables include information about the source term, atmospheric transport and diffusion, and dose and consequence assumptions as well as the operational characteristics employed by each of the models. While the WIND System atmospheric models and RASCAL both represent the transport of radiological materials using a Gaussian assumption, the approach is quite different.

The capabilities of REACTOR ACCIDENT are listed in Tables $1-4$ only when there are significant differences between it and PUFF/PLUME. The most important difference is the way each model handles the source term. The user must enter the source strength in PUFF/PLUME, but REACTOR ACCIDENT is specifically designed to compute the source strength due to a fuel damage incident at SRS reactor facilities.

The largest differences arise in how meteorological data is specified and incorporated into the models and in the way each of the modeling systems handles the graphical and tabular output of the results. For instance, RASCAL restricts the user to specify up to four periods of meteorological data that must be entered manually. PUFF/PLUME, 2DPUF, and REACTOR ACCIDENT allow the user to automatically access a combination of observed data from the onsite towers and NWS foreca ts. Consequently, data entry errors are eliminated and the time required to enter data is reduced when meteorological data is accessed automatically. If the user decides that meteorological data must be entered manually, the user may specify up to 12 $\mathrm{hr}$ of data in PUFF/PLUME and $23 \mathrm{hr}$ of data in 2DPUF. The meteorological data may automatically change at hourly intervals in the WIND System codes, but RASCAL restricts the user to specify the time in which the meteorological data is valid.

The type of graphical and tabular output produced by the WIND System atmospheric models and RASCAL is significantly different. A plume in RASCAL is depicted as a series of ASCII characters, each representing a dose interval, that is overlaid on a series of concentric circles around the release location. While the user gets a feel of the overall direction and distance the plume has traveled, additional information would be necessary to determine the specific areas that would be affected by the plume. In contrast, the WIND System atmospheric models produce detailed maps of the SRS with the plume represented by contours of various levels of dose. In this way, the user can immediately determine the facilities at the SRS that may be affected by a particular release. Long-range transport may occur over a $24 \mathrm{hr}$ period for sufficiently strong winds; therefore, some of the WIND System atmospheric codes produce a contour plot of a plume overlaid on a regional map that may extend hundreds of miles from the site. RASCAL was designed for the initial phase of an accidental release; therefore, predictions are only produced out to $25 \mathrm{mi}$ from the release location. The maximum dose at $0.5,1.0,2.0$, $5.0,10.0$, and $25.0 \mathrm{mi}$ distances from the release location are listed in the tabular output of RASCAL. Under certain atmospheric conditions, the location of the maximum dose may fall between the default distances chosen by RASCAL. The WIND System atmospheric models produce high-resolution tabular output so that the maximum dose of a plume may be captured. This resolution depends on the advect $n$ time step specified by the user or determined by the models. 
Some of the features of the WIND System atmospheric models, not found in RASCAL, that may be important factors for emergency response applications at SRS include:

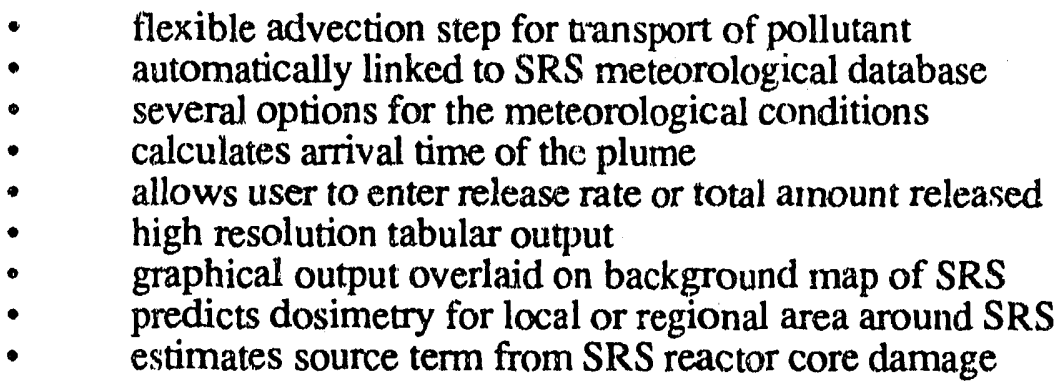

Some of the features of RASCAL, not found in the WIND System atmospheric models, that may be important factors for emergency response applications at SRS include:

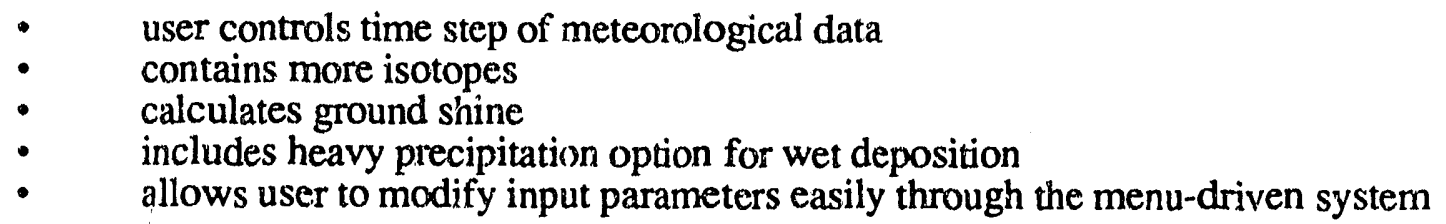

It is clear from Tables $1-4$ that the WIND System atmospheric codes were specifically designed for the SRS and RASCAL was designed as a more generic code to be employed at commercial nuclear power plants. It is also useful to compare the numerical output of the models to verify that the WIND System models are qualitatively producing the correct results.

\subsection{COMPARISON OF THE NUMERICAL RESULTS}

The WIND System atmospheric models and RASCAL were run using the same source term and meteorological data. A summary of the input parameters used for the models in this study is presented in Table 5. Table 6 provides a list of the cases that were employed by each of the models. The input parameters were held constant in time for all cases except case 15 . The source strength was $60 \mathrm{Ci}$ over a $60 \mathrm{~min}$ period for "plume" calculations and $15 \mathrm{Ci}$ over a 15 min period for "puff" calculations.

The emphasis of this study is placed on keeping the meteorological parameters fixed in time throughout the calculations for most of the cases examined in this study. In this way, the meteorological situations in which there are significant differences between the model results can be easily identified. It is more difficult to compare the results produced by the models when the meteorological conditions vary in time because any differences in the results would then be due to a combination of factors. In addition, RASCAL is designed to calculate the transport of radiological materials in the initial phase of an emergency response situation. In emergency response situations, constant meteorological conditions is a good assumption close to the release location over a relatively short period of time.

A broad range of meteorological data was chosen for the input parameters. A relatively narrow range of source term parameters were used because it was not the purpose of this s.ddy to compare the models for every potential accidental release. For instance, all of the cases employed the same release height because the most likely release location to the atmosphere for SRS applications will be at the proxluction facility stacks. Only two release durations were used. A release duration of $15 \mathrm{~min}$ was used for a single "puff" calculation, and a release duration of 60 min was used for a "plume" calculation. Only two isotopes, $\mathrm{l}-132$ and $\mathrm{Pu}-238$, were used. 
Since the WIND System codes and RASCAL are not exactly the same, some additional consideration to the input parameters had to be made. For instance, RASCAL allows the user to select the Pasq"ill-Gifford stability class; however, the dispersion parameters in the WIND System codes are determined from the horizontal $\left(\sigma_{R}\right)$ and vertical fluctuation $\left(\sigma_{e}\right)$ of the wind direction measured at the SRS meteorological towers?. The specific values of $\sigma_{a}$ and $\sigma_{e}$ that were used for each stability class are also listed in T"able 5. Wet deposition is treated differently between the models as well. RASCAL has light ( $<1 \mathrm{~mm} \mathrm{hr}-1)$, moderate $\left(1-10 \mathrm{~mm} \mathrm{hr}^{-1}\right)$, and heavy ( $>10 \mathrm{~mm} \mathrm{hr}^{-1}$ ) categories for rainfall, bui PUFF/PLUME only has two categories consisting of light $\left(1 \mathrm{~mm} \mathrm{hr^{-1 }}\right)$ and heavy $\left(5 \mathrm{~mm} \mathrm{hr}^{-1}\right)$. RASCAL's moderate and PUFF/PLUME's heavy categories are more comparable and there is no equivalent to RASCAL's heavy category in PUFF/PI UME; therefore, case 13 was run only for RASCAL. The total calculation period for RASCAL was usually set to $3 \mathrm{hr}$, which was enough time to transport the radiological materials across $25 \mathrm{mi}$. For low wind speeds, the total calculation perior for RASlai was set to $12 \mathrm{hr}$.

The resulis trom the WIND System atmospheric models are available at user-specified positions. In the figures in this section, a direct comparison with RASCAL (which has output available at six downwind locations) is made with only a portion of the data available from the WiND System atmospheric models.

\subsection{AREA EVACUATION and RASCAL}

In this study, the original version Uf AREA EVACUATION cannot be used because it does not (1) generate results put to 25 mi downwind of the source, and (2) produce tabular output of the results. Therefore, a modified version of AREA EVACUATION was sreated to perform these two tasks so that the results from RASCAL and AREA EVACUATYON could be compared quantitatively.

The centerline inhalation dose predicted by AREA EVACUATION and RASCAL is shown in Figs. 1 - 4. In most cases, the results produced by AKEA EVACUATION and RASCAL were quantitatively similar and exhibited the behavior that is to be expected from a Gaussian model. However, there were a few instances where the models pioduced significantly different results. Low wind speeds produced the largest difference between AREA EVACUATION and RASCAL, as shown in Fig. 1, where the results differed by nearly an order of magnitude 25 mi downwind of the source. In Fig. 2 , the models also differ substantially close to the source for stable atmospheric conditions. The results from case 7 were not plotted on Fig. 3 because the results from both models were identical to those produced by case 1 . It is interesting to note that in both models, the change in boundary-layer height for this case did not affect the dose downwind of the source for neutral atmospheric conditions.

Some of the differences in the results are probably due to the dose factors employed by the models. For instance, the dose factor for 1-132 in AREA EVACUATION is $0.1260 \mathrm{rem} \mathrm{m}$ $\mathrm{Ci}^{-1} \mathrm{~s}^{-1}$ assuming an adult breathing rate of $1.37 \mathrm{~m}^{3} \mathrm{hr}^{-1}$ and a $50 \mathrm{yr}$ dose commiment; while the dose factor for I-132 in RASCAL. is $0.1322 \mathrm{rem} \mathrm{m}^{3} \mathrm{Ci}^{-1} \mathrm{~s}^{-1}$ assuming a child breathing rate of $0.61 \mathrm{~m}^{3} \mathrm{hr}^{-1}$ and a $50 \mathrm{yr}$ dose commitment. For Pu-238, the dose factor in RASCAL is $66,083 \mathrm{rem} \mathrm{m}^{3} \mathrm{Ci}^{-1} \mathrm{~s}^{-1}$ and in AREA EVACIJATION it is $175,000 \mathrm{rem} \mathrm{m}^{3} \mathrm{Ci}^{-1} \mathrm{~s}^{-1}$. Given that AREA EVACUATION is designed to assist decision makers in the relocation of workers aild adult visitors within a particular facility, an adult breathing rate is more appropriate. This also explains explains why the inhalation dose predicted by RASCAL from I-132 was higher than for AREA EVACUATION as shown in Fig. 4. As expected, RASCA.L predicted a somewhat lower dose for Pu-238 than AREA EVACUATION. 


\subsection{PUFF/PLUME and RASCAL}

The centerline inhalation dose predicted by PUFF/PLUME and RASCAL for a "plume" is shown in Figs. 5 - 10. As in AREA EVACUATION, there were a few instances where the model results differsd substantially. Low wind speeds produced the largest difference between PUFF/PLUME and RASCAL as shown in Fig. 5. When compared to Fig. 1, it is clear that the results from PUFF/PLUME were closer to those produced by RASCAL than AREA EVACUATION. The effect of low wind speed was examined in more detail in Fig. 6, in which all of the wind speeds were $1 \mathrm{~m} \mathrm{~s}^{-1}$ and only the atmospheric stability was changed. It was found that for low wind speeds, the inhalation dose calculated by PUFF/PLUME and RASCAL differed substantially for neutral and unstable conditions; however, the doses were nearly the same for stable atmospheric conditions. Therefore, a gross generalization that PUFF/PLUME and RASCAL. will produce substantially different doses for low wind speeds cannot be madi

In contrast to AREA EVACUATION, PUFF/PLUME and RASCAL produced nearly the same dose close to the source for stable atmospheric conditions as shown in Fig. 7. As in AREA EVACUATION, the change in the boundary-layer height did not affect the dose downwind of the source for neutral atmospheric conditions; thereiore, the results from case 7 were not plotted on Fig. 8. Since PUFF/PLUME employs the same dose factors as AREA EVACUATTON, the results presented in Fig. 9 for I-132 and Pu-2.38 were nearly identical to those shown in Fig. 4. As depicted in Fig. 10, deposition reduced the dose in RASCAL more than it did in PUFF/PLUME. PUFF/PLUME does not have an equivalent to RASCAL's heavy precipitation category $\left(>10 \mathrm{~mm} \mathrm{hr}^{-1}\right.$ ). In that case the dose was significantly reduced by deposition $25 \mathrm{mi}$ downwind of the source. The case for light rain produced nearly the same results for both models.

The centerline inhalation dose calculated by PUFF/PLUME and RASCAL for a single "puff", assuming a release duration of $15 \mathrm{~min}$, is presented in Figs. $11-16$. The results in these figures are qualitatively similar to the runs for a "plume" except for the magnitude of the rose, however, there are many instances where the differences between PUFF/PLUME and RASCAL, were reduced. This may be the result of the fact that the dispersion parameters employed by PUFF/PLUME for a "puff" may be significantly different than those for a "plume"7.

The results produced by PUFF/PLUME: and RASCAL for the variable meteorological situation (case 15) were very similar (not shown).

\subsection{DPUF and RASCAL}

The centerline inhalation dose calculated by 2DPUF and RASCAL for a single "puff" are shown in Figs. 17 - 20. The results produced by 2DPUF and RASCAL were qualitatively similar; however, 2DPUF was the one WIND System atmospheric model that produced the largest quantitative differences. As in PUFF/PLUME, low wind speeds produced tie largest difference between 2DPUF and RASCAL as shown in Fig. 17. When compared to Fig. 11, it is clear that the results frorn PUFF/PLUME were closer to those produced by RASCAL than 2DPUF, RASCAL and 2DPUF differed by nearly an order of magnitude 25 mi downwind of the source. In addition, 2DPUF and RASCAL differed more for neutral stability conditions in Fig, 18 when compared to PUFF/PLUME. 2DPUF and RASCAL differed significantly for neutral stability conditions when the boundary-layer height was changed to $1000 \mathrm{~m}$ in case 7 in Fig. 19. 2DPUF allowed the "puff" to grow more in the vertical direction; therefore, the dose decreased dramarically downwind with distance. It can be expected that 2DPUF will produce significantly lower doses than RASCAL for neutral and stable armospheric conditions with 
relatively large boundary-layer heights. The effect of the dose factor on the results for I-132 and Pu-238 was similar to AREA EVACUA TION, as shown in Fig. 20, because 2DPUF employed the same dose factors.

2DPUF was the only WIND System model used to compare cloud shine dose with RASCAL. The centerline cloud shine dose calculated by RASCAL and 2DPUF for a single "puff" were compared and are presented in Figs. 21 - 24. It was not uncommon that the cloud shine dose predicted by the models differed by an onder of magnitude. Again, the largest differences were found in the low wind speed case, where RASCAL produced a dose that was approximately twenty-five times larger than 2DPUF as shown in Fig 21. RASCAL sometimes produced a minimum in the cloud shine dose somewhere between the release location and $25 \mathrm{mi}$ downwind of the source. This feature was also depicted in the user documentation ${ }^{9}$; however, it dose not seem physically realistic and an explanation of this behavior is not included in the user documentation. The results for neutral atmospheric stability conditions were nearly ides:tical for both models with 1-132; however, they differed by nearly an order of magnitude for Pu-238 as seen in Fig. 24.

\subsection{WIND System Atmospheric Models and RASCAL}

A direct comparison of all of the WIND System atmospheric models and RASCAL was made from the results presented in Figs. 1 - 24. The doses were compared at the 0.5, 1.0, 2.0, 5.0, 10.0 , and $25.0 \mathrm{mi}$ downwind distances and the results are presented in Table 7 . It was found that approximately $70 \%$ of the paired, predicted dose values are within a factor of two of each other; $19 \%$ are within a factor of two to four, $8 \%$ are within a factor of four to ten, and less than $2 \%$ are greater than a factor of ten. In general, the WIND System models and RASCAL are in close agreement within $10 \mathrm{mi}$ from the source; however, larger differences appear between 10 and $25 \mathrm{mi}$ downwind of the source.

A comparison was also made between RASCAL and the individual WIND System atmospheric models as shown in Table 8. PUFF/PLUME tended to produce dose values that agreed with RASCAL more than AREA EVACUATION or 2DPUF. Approximately $96 \%$ of the results for a "plume" and $95 \%$ of the results for a "puff" from PUFF/PLUME were within a factor of four of R.ASCAL. Approximately 94\% of the results from AREA EVACUATION were within a factor of four of RASCAL. Relatively larger differences were found between 2DPUF and RASCAL for both inhalation and cloud shine dose. Nevertheless, $86 \%$ of the results were within a factor of four for inhalation dose and $67 \%$ of the results were with a factor of four for cloud shine dose.

The numerical results at selected downwind distances for RASCAL, AREA EVACUATION, PUFF/PLUME, and 2DPUF that were used in Figs. 1 - 24 are presented in Tables 9, 10, 11, and 12 respectively.

\subsection{DISCUSSION}

The comparison of the numerical results from RASCAL and the WIND atmospheric models in this study cannot be used to determine which model produces the "best" answer; however, the dose estimates in both modeling systems should be qualitatively similar. To determine which modeling system produces the "best" answer, the numerical results from both modeling systems would have to be compared to observed values taken from a tracer experiment. The purpose of this study was to demonstrate the effect of the various assumptions and formulations used by each of the models on the numerical results. 
When PUFF/PLUME and 2DPUF5 wete compared to observed SF 6 tracer plumes at SRS, it. was found that PUFF/PLUME usually produced "conservative" estimates of the concentration, while 2DPUF produced results that were closer to the observations. In this study, RASCAL was even more "conservative" than PUFF/PLUME and could potentially give over-estirnates of the dose.

One can expect that, on average, the results produced by a WIND System atmospheric model and RASCAL will probably be within a factor of four of one another. However, there will be many instances where the WIND System atmospheric models and RASCAL can differ by more than an order of magnitude. In general, one can expect to find significantly different values of dose for low wind speeds, strong atmospheric stability, and wet deposition and for many atmospheric cases involving cloud shine. In another comparison study with RASCAL, METPAC (developed by Yankee Atomic Electric Company) and RASCAL also produced substantially different results with low wind speeds ${ }^{10} .90 \%$ of the results produced by METPAC were within a factor of four of RASCAL. Some oi the smaller differences in the WIND System atmospheric modeis and RASCAL are probably due to slight differences in the way atmospheric transport and diffusion is handled. The magnitude of the dose factors employed by the models will also contribute to some of the differences.

\subsection{CONCLUSION}

A detailed comparison of the characteristics of tile WIND System atmospheric models and RASCAL was made. It was found thet both modeling systems employ a Gaussian assumption for the transport and diffusion of radiological materials, but the they differed substantially in the way input is entered and the way output is displayed. Nevertheless, using the same input parameters, the WIN. System atmospheric models and RASCAL produced similar 1esults in most situations. It was found that the WIND System atmuspheric model predictions are within a factor of two at least $70 \%$ of the time and are with a factor of four of each otter $89 \%$ of the time. Most of the differences in the doses computed by the models are probably due to the various diffusion parameters and dose factors that are exuployed. Significant differences in the dose between the models can occur for low wind speeds, strong atmospheric stability, and wet deposition and for many atmospheric cases involving cloud shine.

The site-specific and operational features incluaing the automatic input of quality-assured meteorological observations or forecasts, detailed dose values clownwind of the source, sitespecific maps, and relatively short execution times, make the WIND System atmospheric codes more user-friendly and useful in emergency response situations at SRS.

\section{REFERENCES}

1. Fast, J. D., and R. P. Addis. Evaluation Protocol for the WIND System Atmospheric Models. WSRC-RP-91-426, Savannah River Site, Aiken, SC 29808 (1991).

2. Weber, A. H., S. Berman, R. J. Kurzeja, and R. P. Addis. "The MATS Experiments Mesoscale Atmospheric Transport Studies at the Savannah River Site", submitted to Nuclear Safety. (1991).

3. Weber, A. H. "The MATS (Mesoscale Atmospheric Transport Studies) Experiments". Proceedings of the DOE/AMS air pollution model evaluation workshop, Kiawah Island, SC, Vol. 1. DP-1701-1, DuPont de Nemours and Company, Savannah River Laboratory, Aiken, SC 29808 (1984). 
4. Weber, A. H., and R. J. Kurzeja. Proceedings of the DOE/AMS Air Pollution Model Evaluation Workshop, Kiawah Island, SC, Vol. 2. DP-1201-2, DuPont de Nemours and Company, Savannah River Laboratory, Aiken, SC 29808 (1984).

5. Addis, R. P. An Evaluation of SRL Emergency Response Codes using MATS Data. DPST-850715, DuPont de Nemours and Company, Savannah River Laboratory, Aiken, SC 29808 (1985).

6. Hunter, C. H. Weather Information and Display (WIND) System User's Manual. WSRC-TM-90-14, Savannah River Site Aiken, SC 29808 (1990).

7. Garrett, A. J., and C. E. Murphy Jr. A Puff-Plume Atmospheric Deposition Model for use at SRP in Emergency Response Situations. DP-1595, DuPont de Nemours and Company, Savannah River Laboratory, Aiken, SC 29808 (1981).

8. Addis, R. P., and B. L. O'Steen. 2DPUF, A Sequential Gaussian Puff Model. WSRC-RP-90-1208, Savannah River Site, Aiken, SC 29808 (1991).

9. Athey, G. F., A. L Sjoreen, and T. J. McKenna. RASCAL Version 1.3 User's Guide. Oak Ridge National Laboratory, Prepared for Division of Operational Assessment, Office of Analysis and Evaluation of Operational Data, U. S. Nuclear Regulatory Commission, Washington, D. C. (1989).

10. Messier, T. A., and J. J. Hawxhurst, "Comparison of Radiological Assessment Models: METPAC and RASCAL", Proceedings of the Third Topical Meeting on Emergency Preparedness and Response, Chicago, IL, pp 106-109, (1991). 


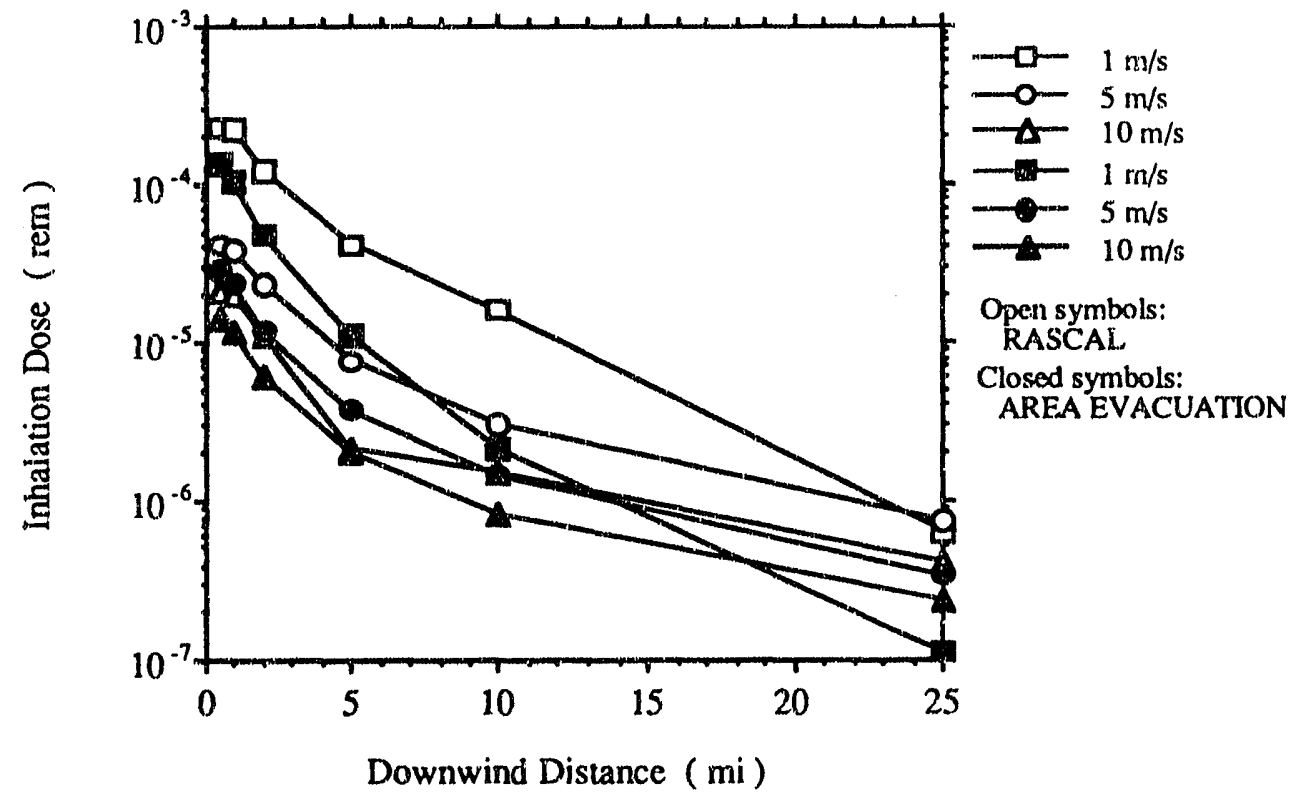

Figure 1. Inhalation dose calculated by AREA EVACUATION and RASC.AL for a $60 \mathrm{~min}$ release with various wind speeds (cases $1,2,3$ from Table 5)

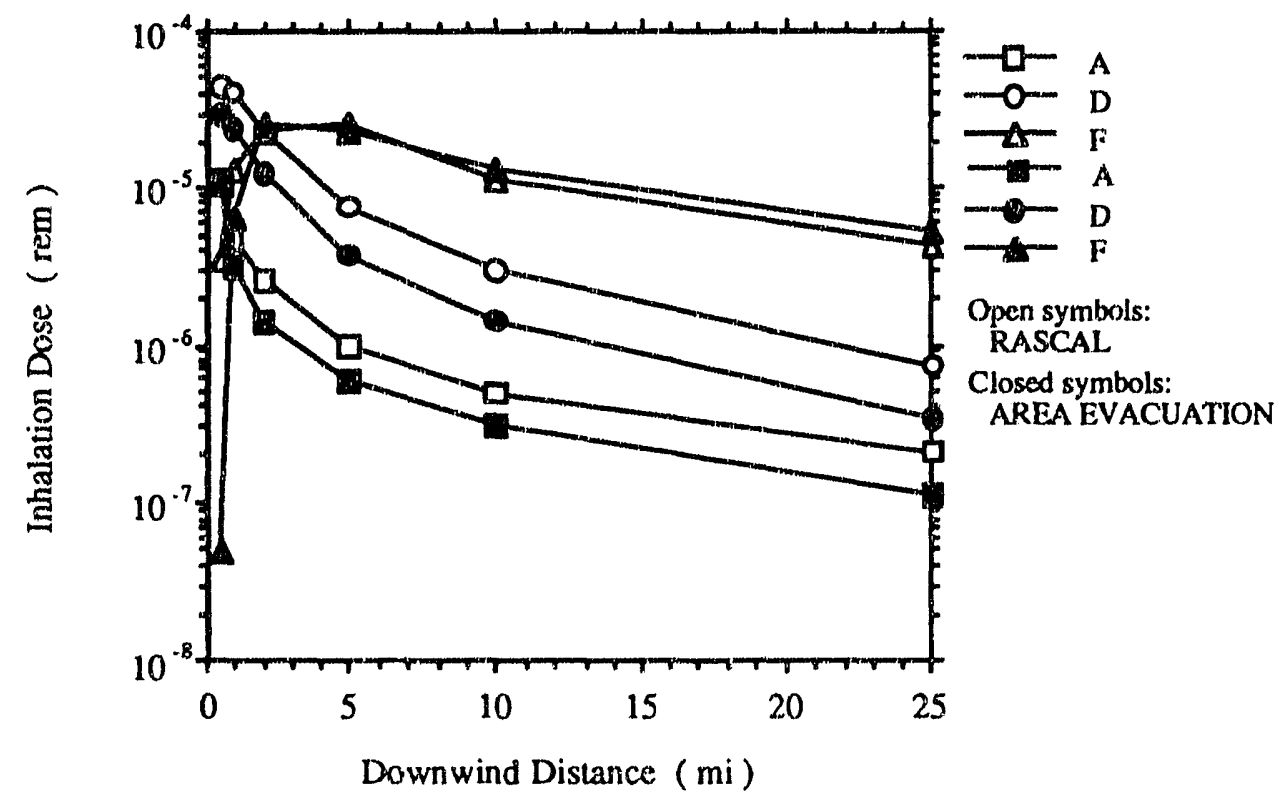

Figure 2. Inhalation dose calculated by AREA EVACUATION and RASCAL for a $60 \mathrm{~min}$ release with various atmospheric stabilities (cases 1, 4, 5 from Table 5) 


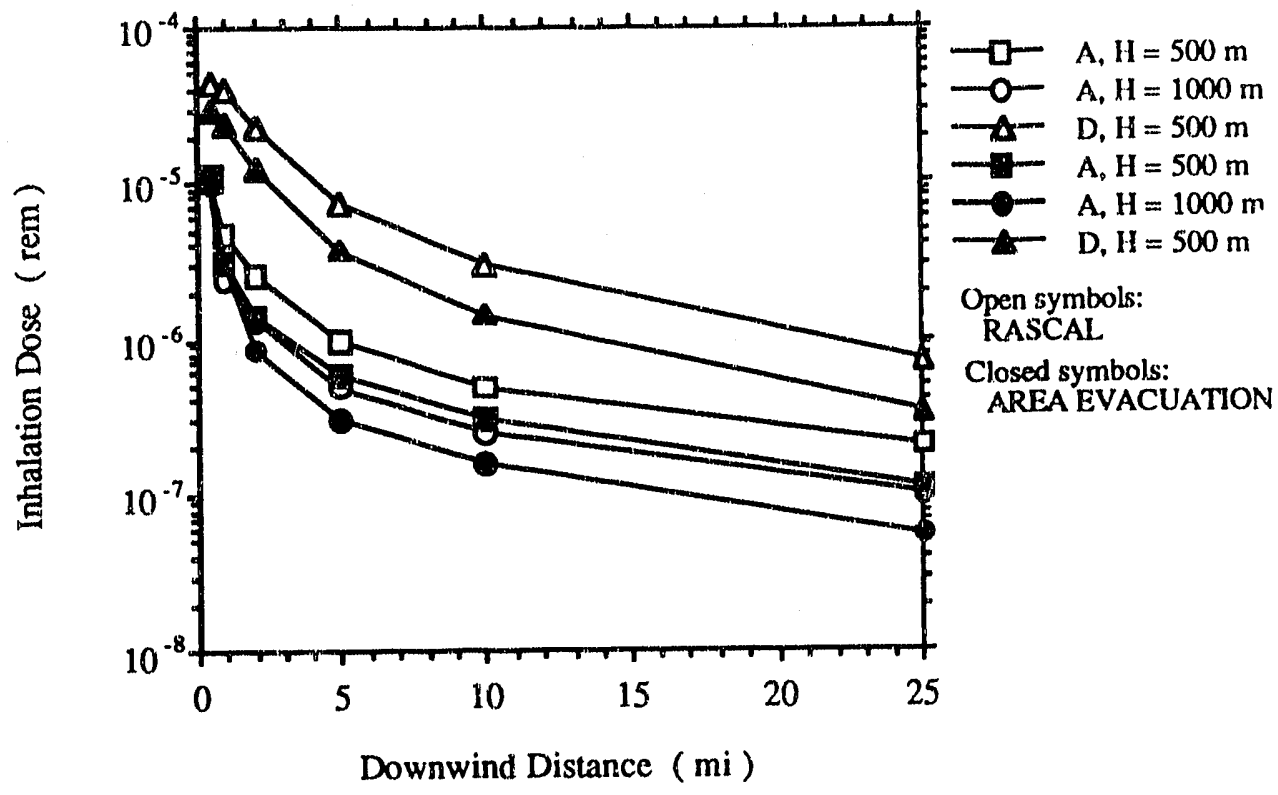

Figure 3. Inhalation dose calculated by AREA EVACUATION and RASCAL for a 60 min release with various boundary-layer depths (cases 1 , 4, 6 from Table 5)

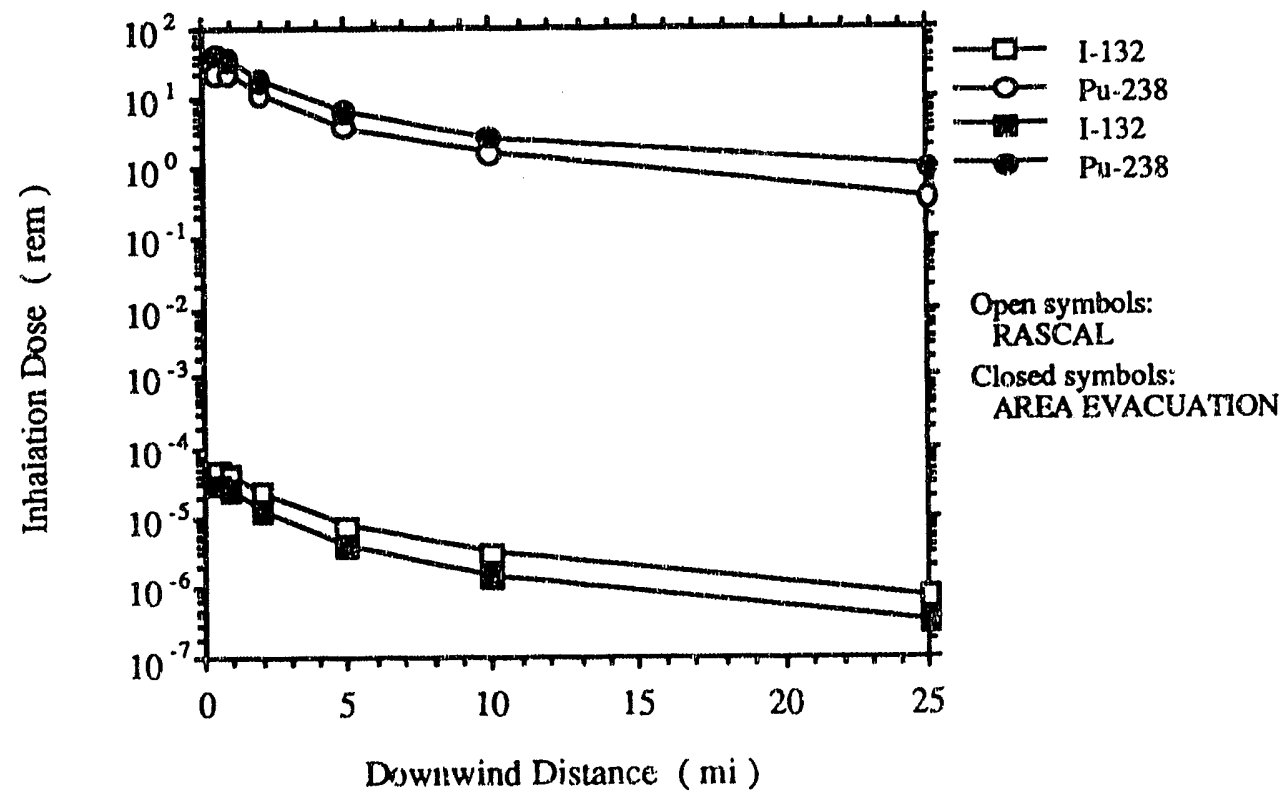

Figure 4. Inhalation dose calculated by AREA EVACUATION and RASCAL for a $60 \mathrm{~min}$ release with two isotopes (cases 1, 8 from Table 5) 


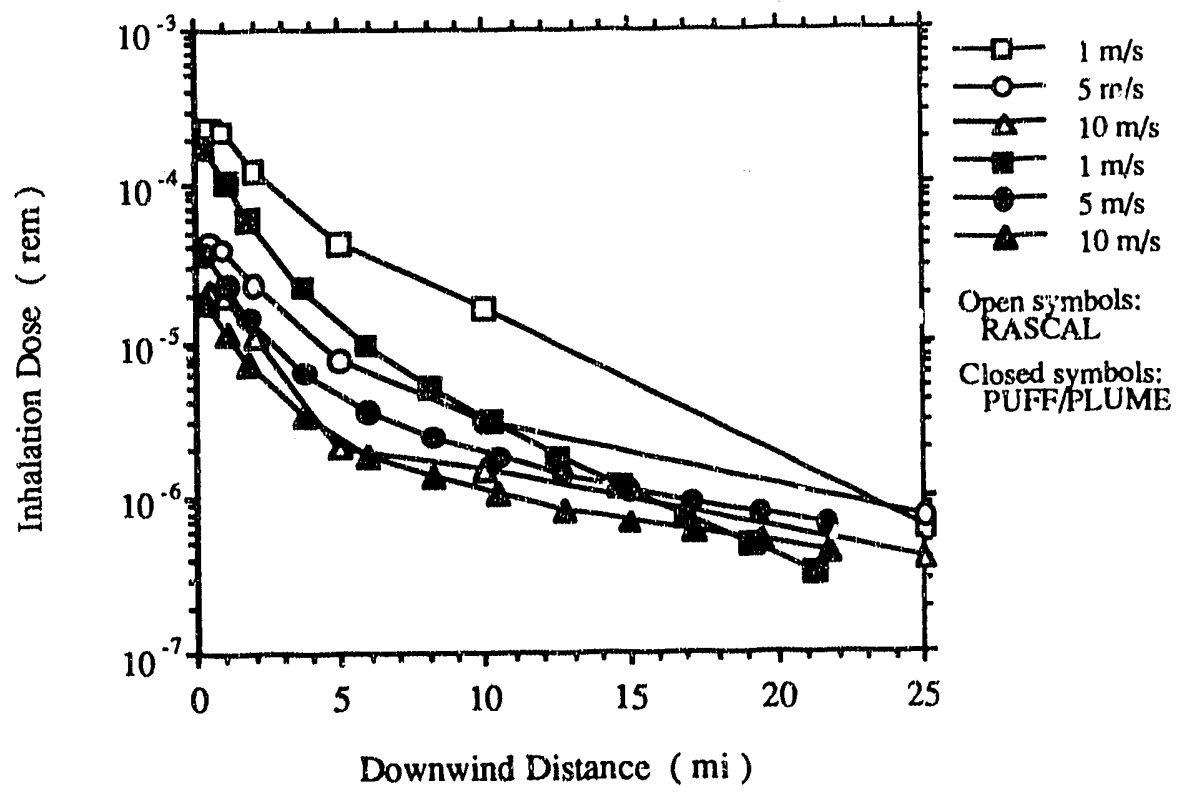

Figure 5. Inhalation dose calculated by PUFF/PLUME and RASCAL for a 60 min release with various wind speeds (cases 1, 2, 3 from Table 5)

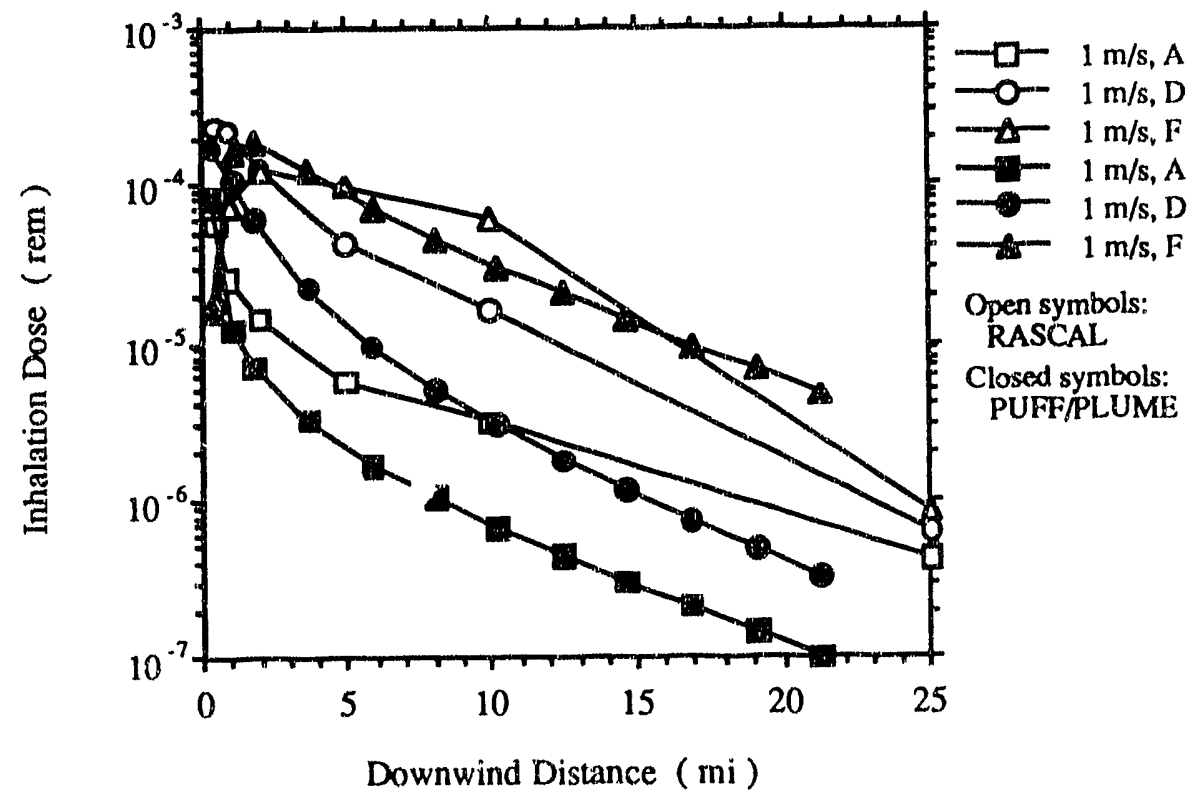

Figure 6. Inhalation dose calculated by PUFF/PLUME and RASCAL for a $60 \mathrm{~min}$ release with various atmospheric stabilities and a wind speed of $1 \mathrm{~m} \mathrm{~s}^{-1}$ (cases, 2, 9, 10 from Table 5) 


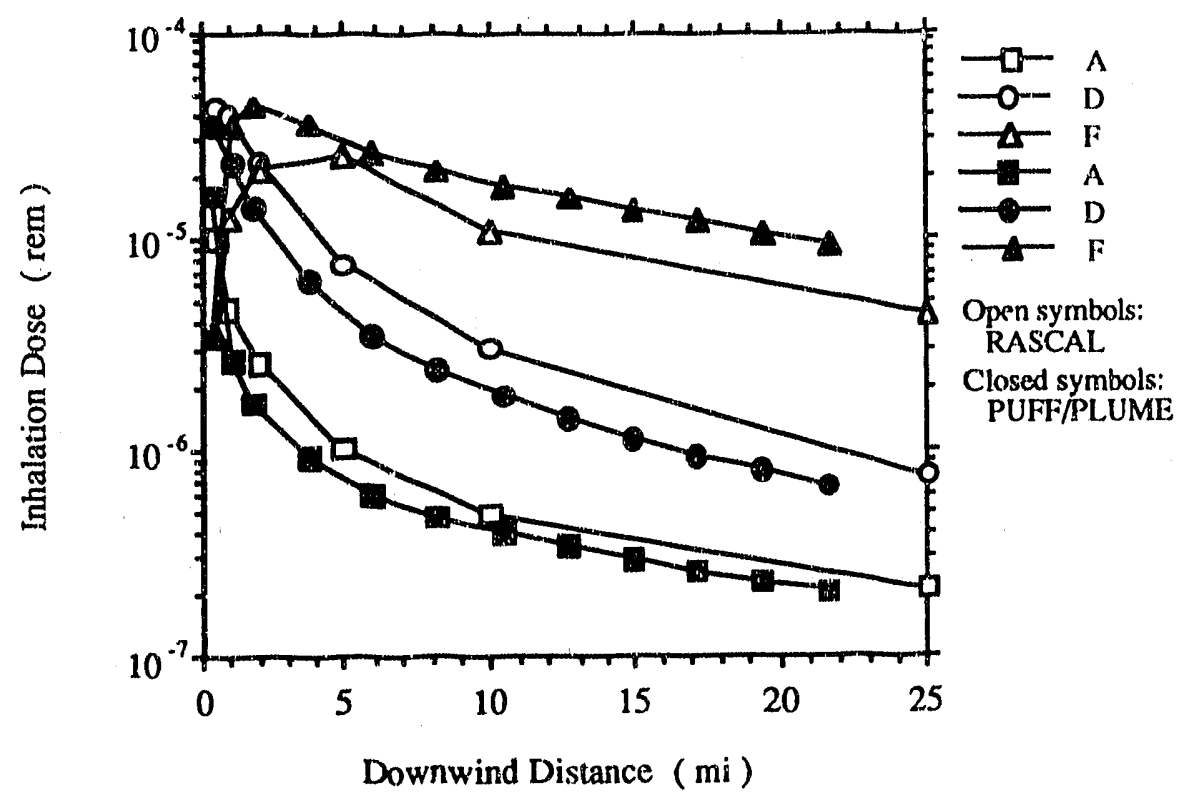

Figure 7. Inhalation dose calculated by PUFF/PLUME and RASCAL for a 60 min release with various atmospheric stabilities (cases 1, 4, 5 from Table 5)

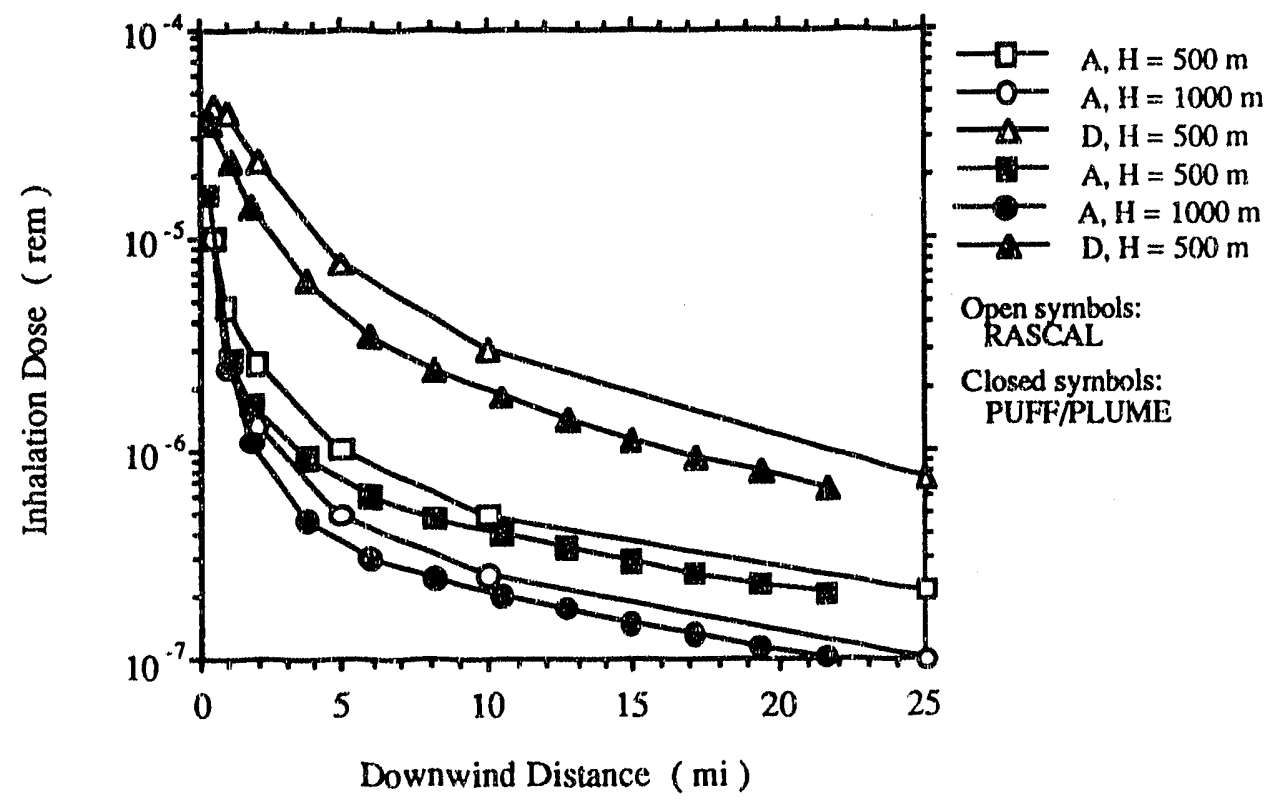

Figure 8. Inhalation dose calculated by PUFF/PLUME and RASCAL for a $60 \mathrm{~min}$ release with various boundary-layer depths (cases 1, 4, 6 from Table 5) 


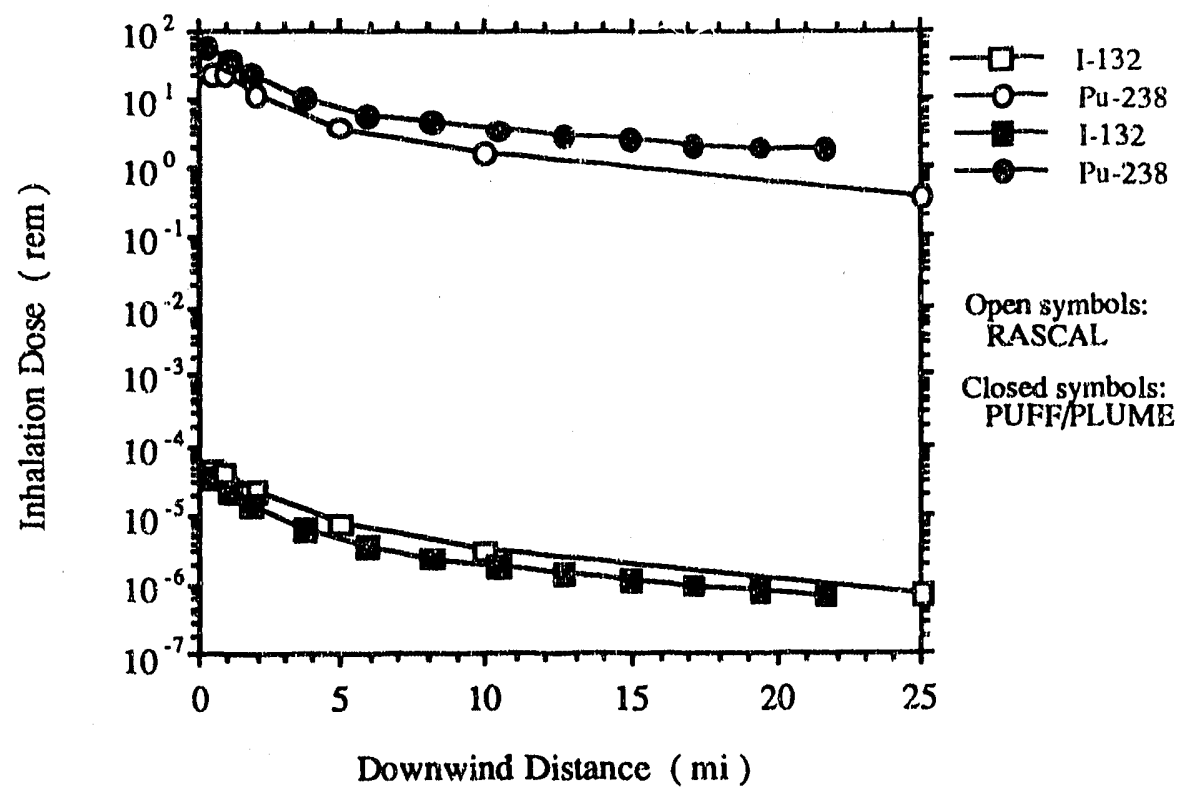

Figure 9. Inhalation dose calculated by PUFF/PLUME and RASCAL for a $60 \mathrm{~min}$ release with two isotopes (cases 1,8 from Table 5)

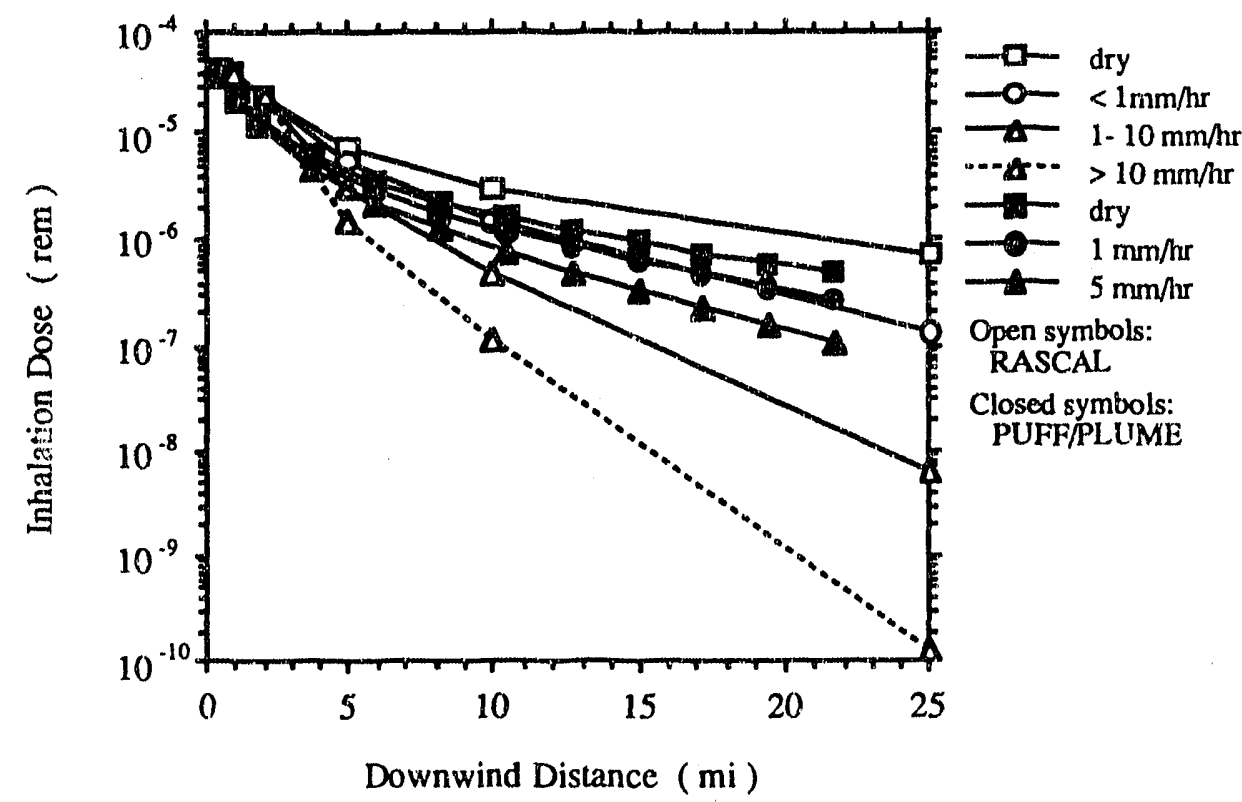

Figure 10. Inhalation dose calculated by PUFF/PLUME and RASCAL for a $60 \mathrm{~min}$ release with various dry and wet deposition rates (cases 1 , $11,12,13,14$ from Table 5) 


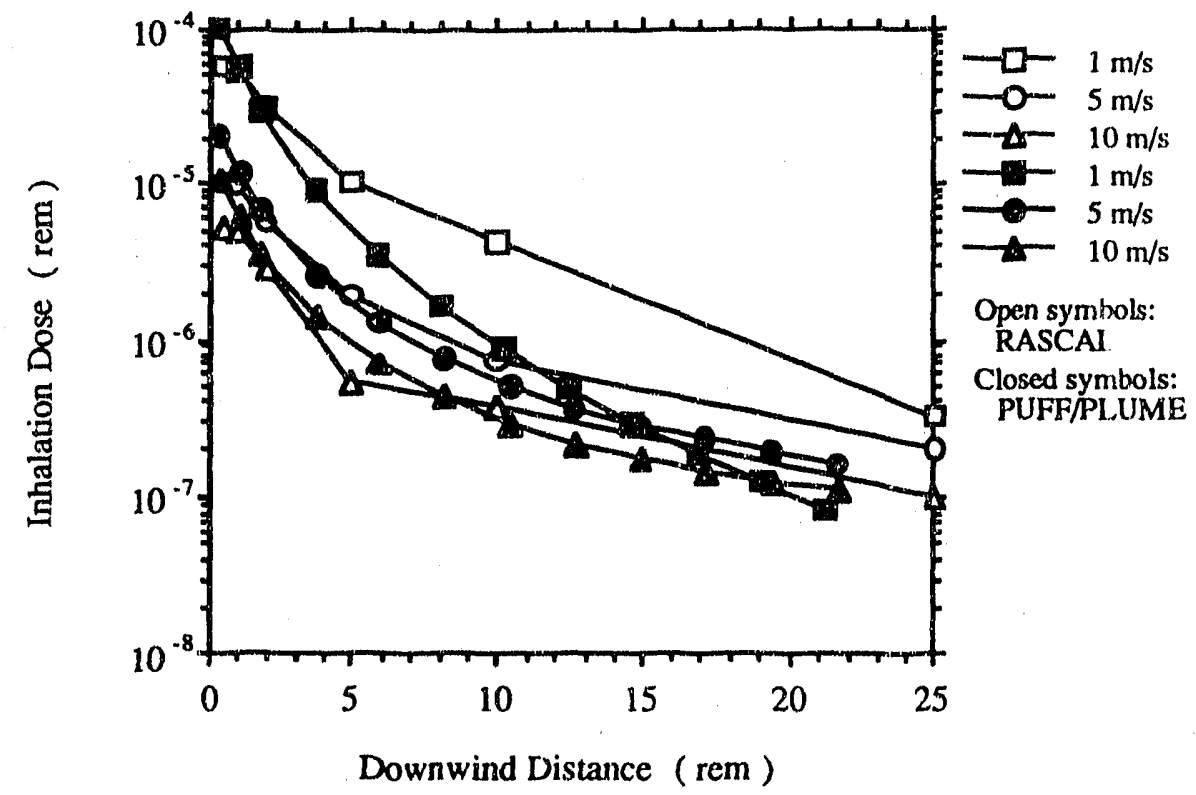

Figure 11. Inhalation dose calculated by PUFF/PLUME and RASCAL for a $15 \mathrm{~min}$ release with various wind speeds (cases $1,2,3$ from Table 5)

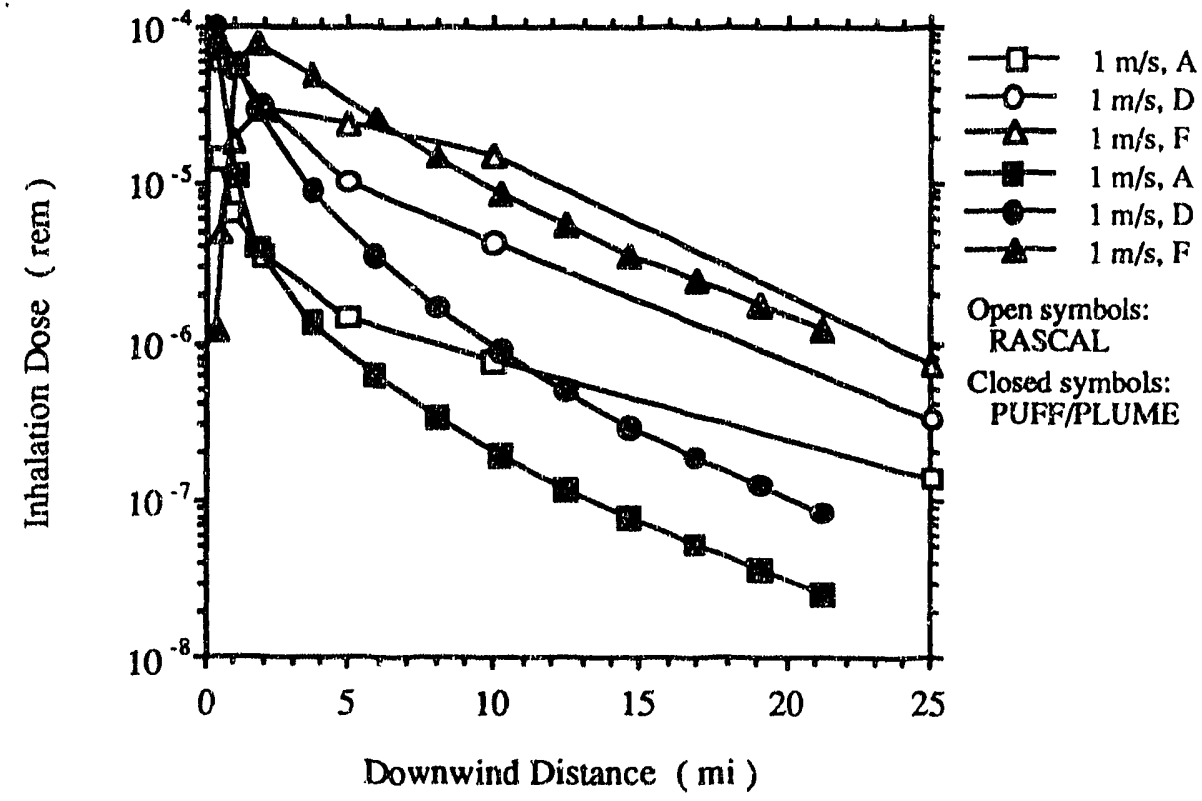

Figure 12. Inhalation dose calculated by PUFF/PLUME and RASCAL for a 15 min release with various atmospheric stabilities and a wind speed $1 \mathrm{~m} \mathrm{~s}^{-1}$ (cases 2, 9, 10 from Table 5) 


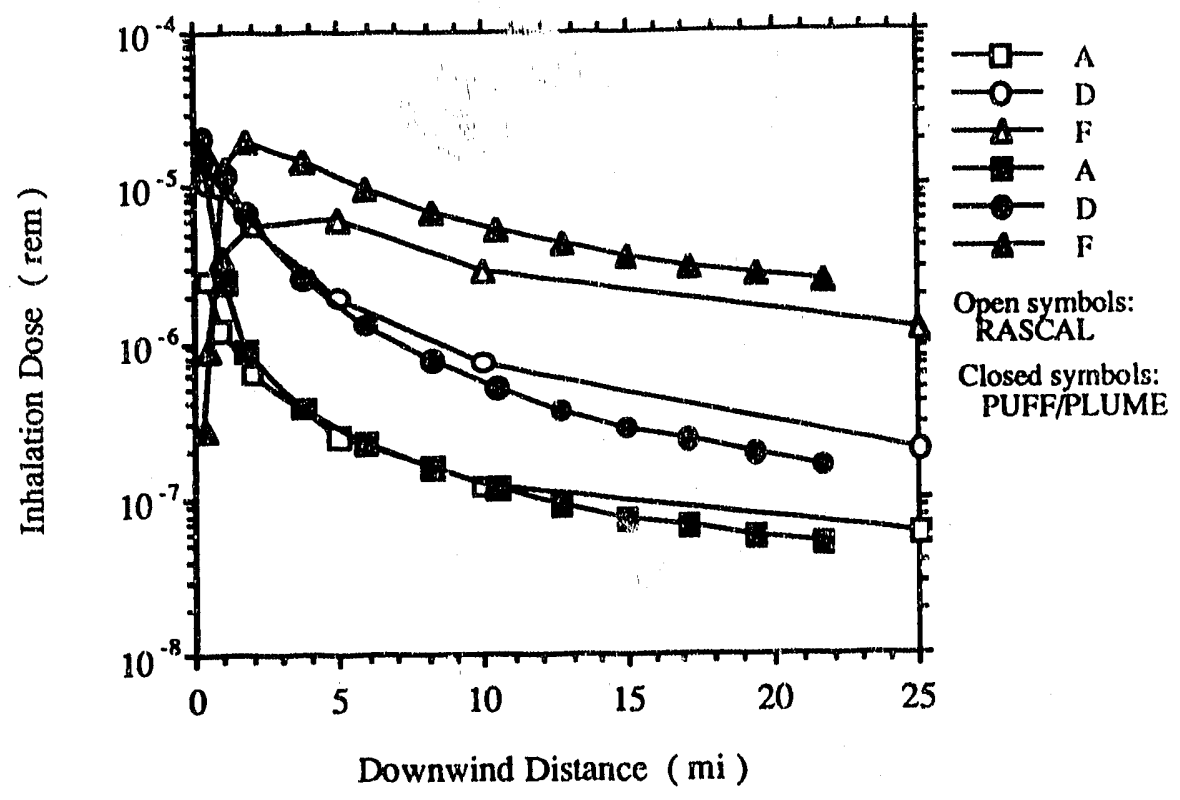

Figure 13. Inhalation dose calculated by PUFF/PLUME and RASCAL for a $15 \mathrm{~min}$ release with various atmospheric stabilities (cases $1,4,5$ from Table 5)

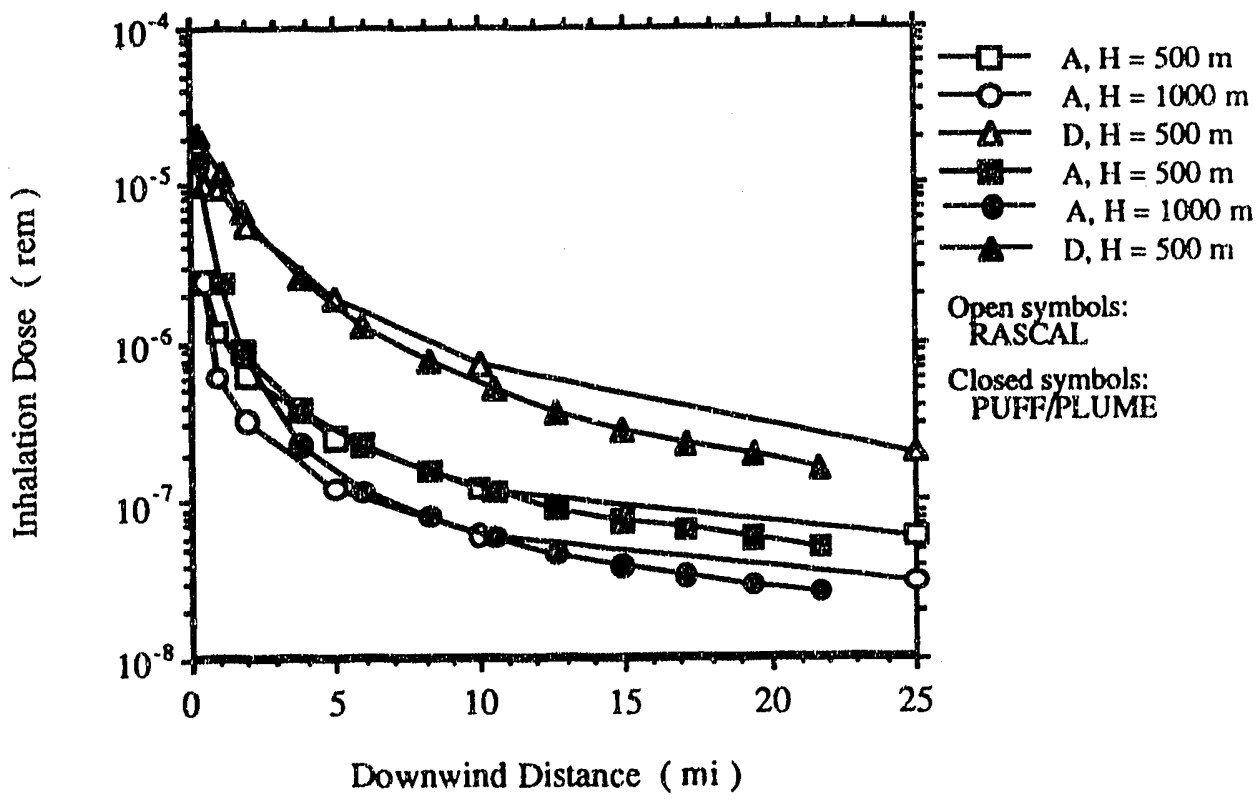

Figure 14. Inhalation dose calculated by PUFF/PLUME and RASCAL for a 15 min release with various boundary-layer depths (cases $1,4,6$ from Table 5) 


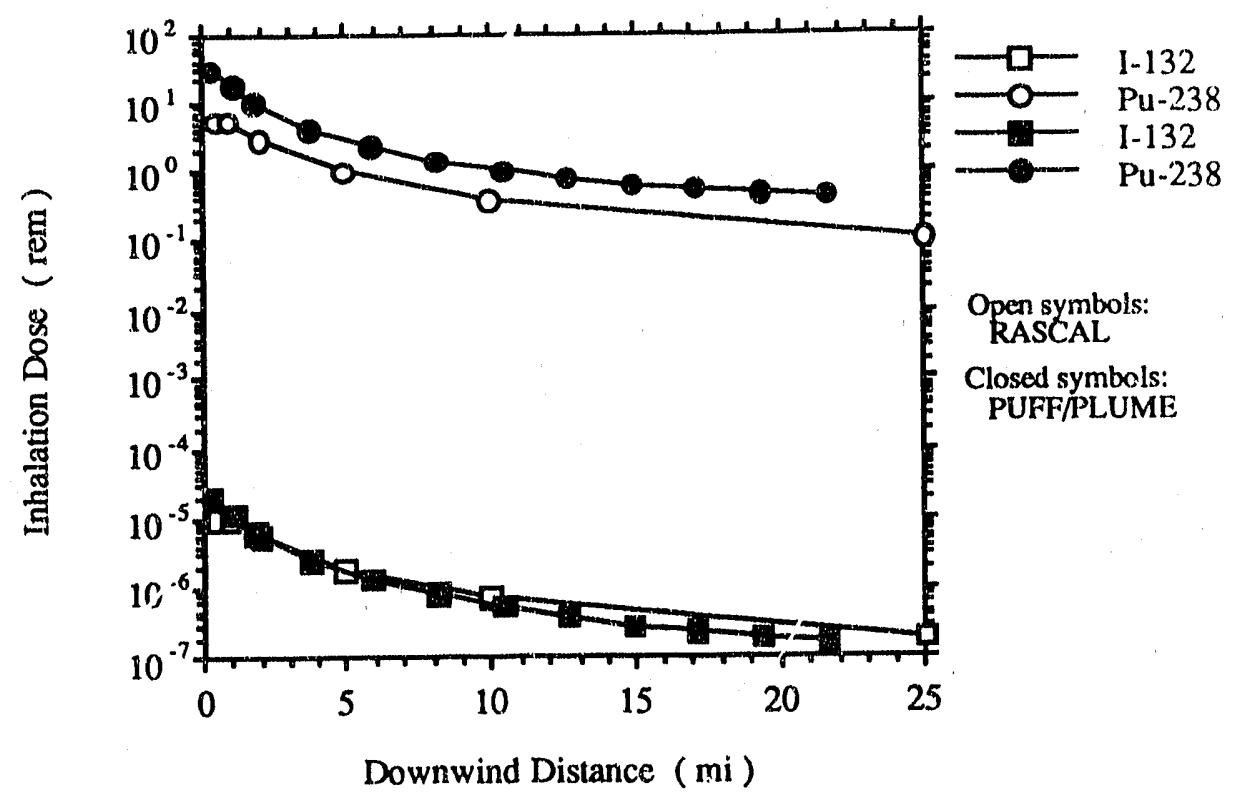

Figure 15. Inhalation dose calculated by PUFF/PLUME and RASCAL for a $15 \mathrm{~min}$ release with two isotopes (cases 1,8 from Table 5)

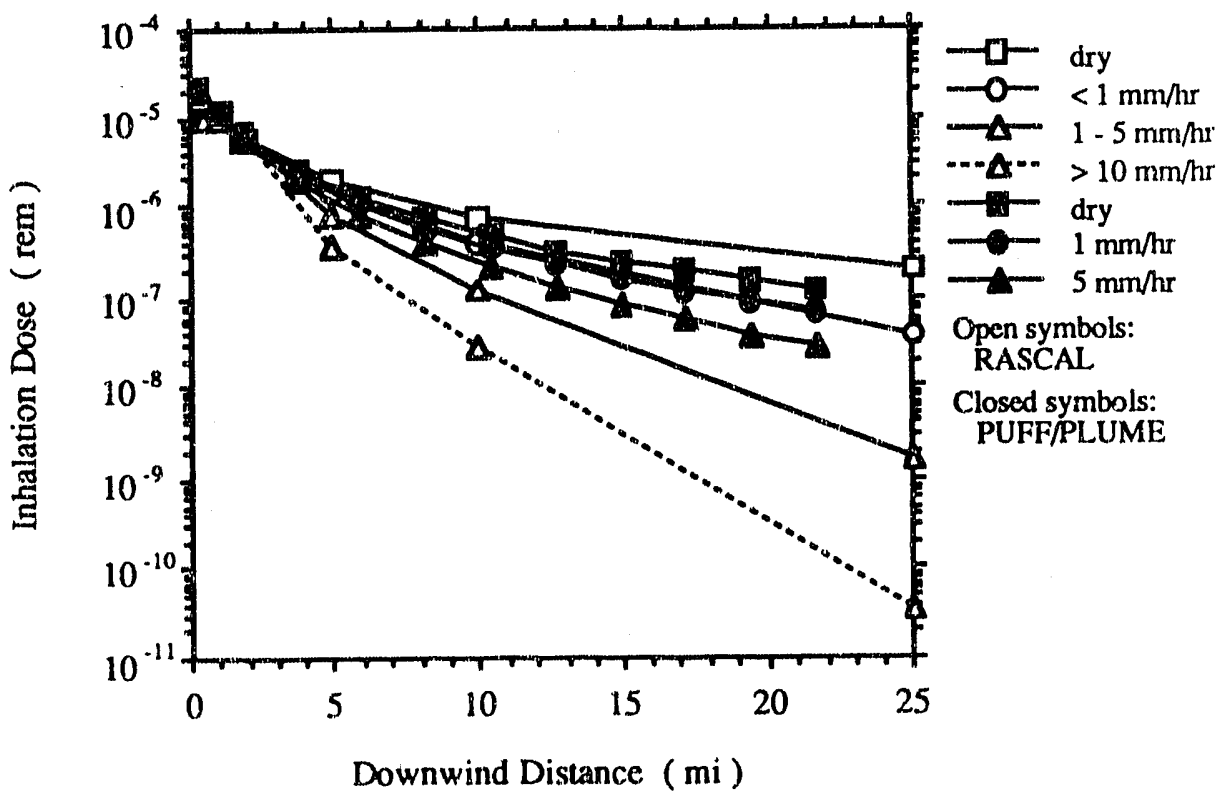

Figure 16. Inhalation dose calculated by PUFF/PLUME and RASCAL for a 15 min release with various dry and wet deposition rates (cases 1 , $11,12,13,14$ from Table 5) 


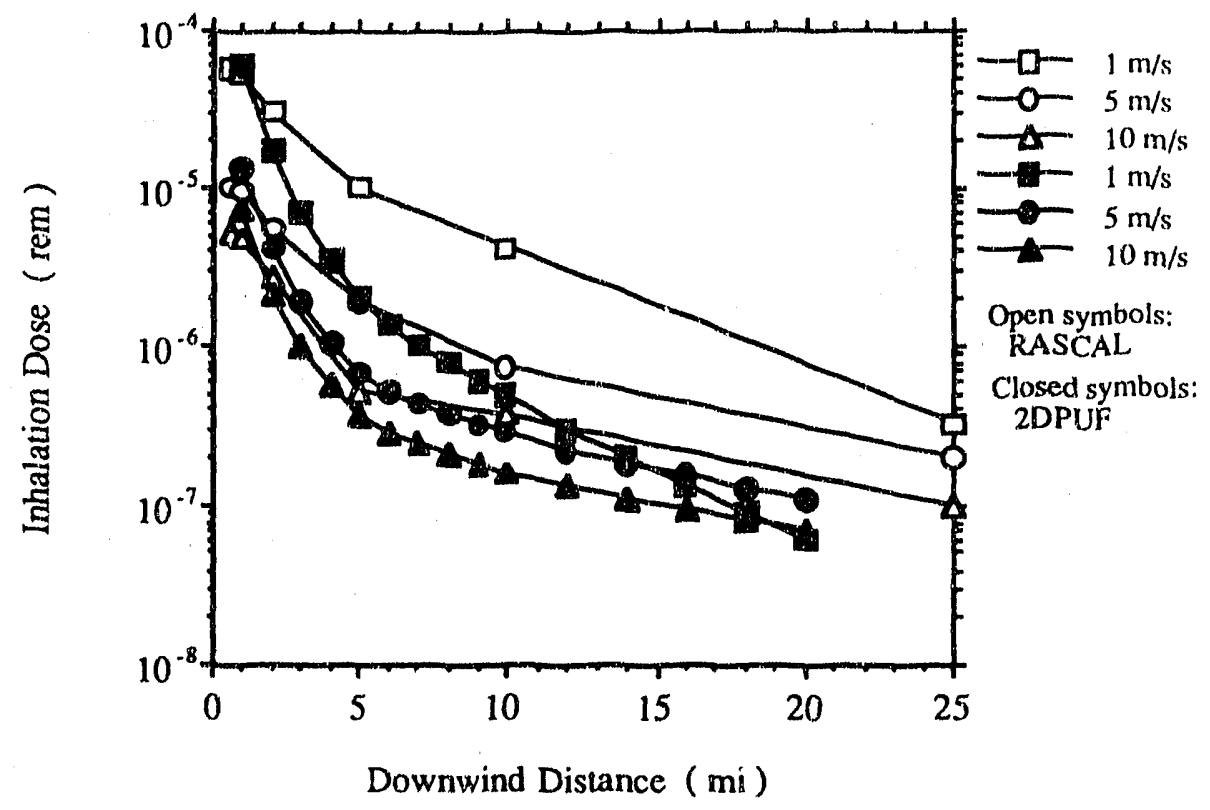

Figure 17. Inhalation dose calculated by 2DPUF and RASCAL for a $15 \mathrm{~min}$ release with various wind speeds (cases 1, 2, 3 from Table 5)

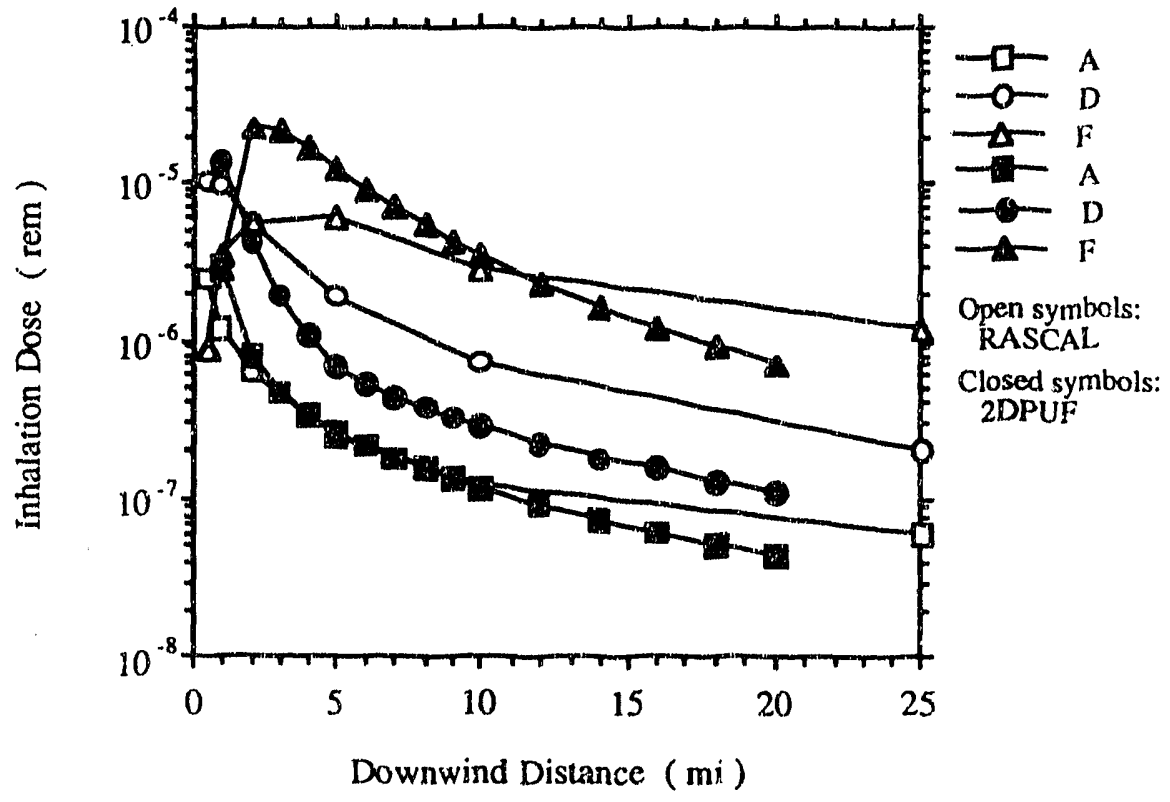

Figure 18. Inhalation dose calculated by 2DPUF and RASCAL for a $15 \mathrm{~min}$ release with various atmospheric stabilities (cases $1,4,5$ from Table 5) 


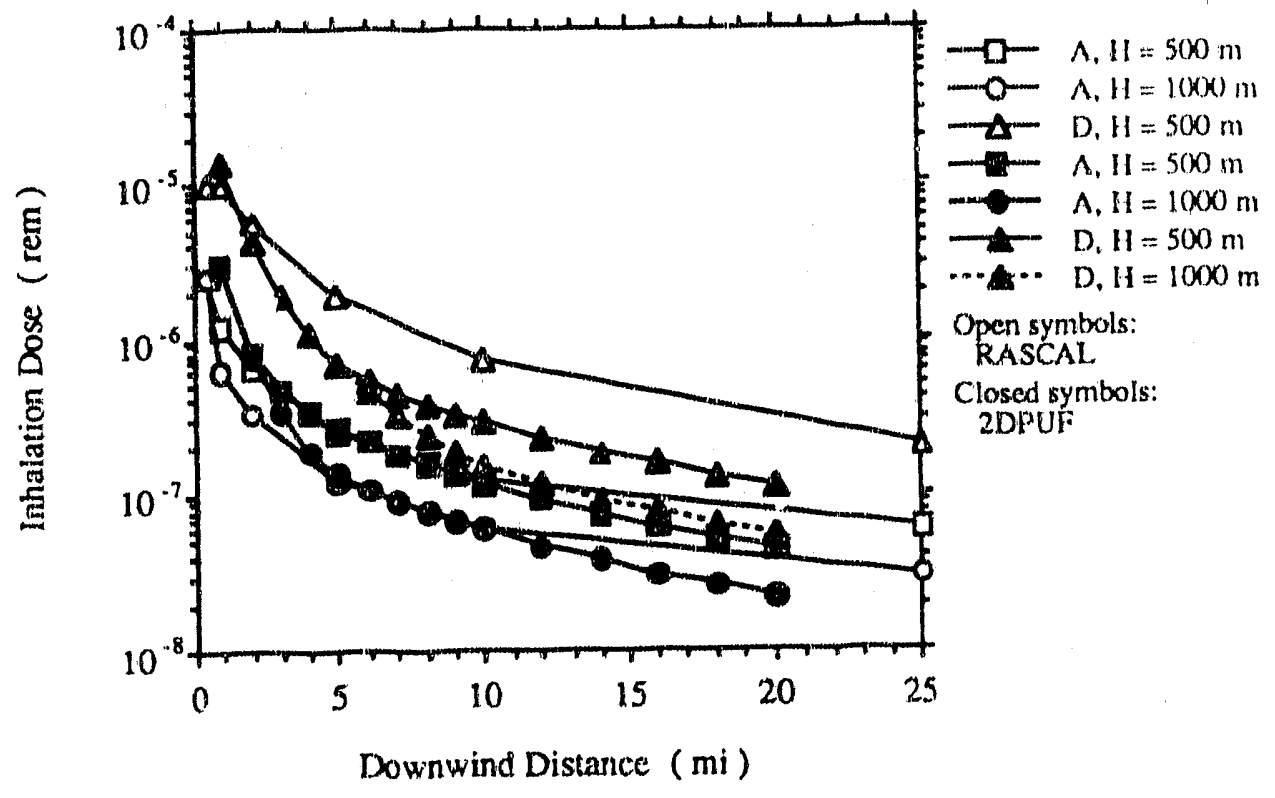

Figure 19. Inhalation dose calculated by 2DPUF and RASCAL for a $15 \mathrm{~min}$ release with various boundary-layer depths (cases $1,4,6,7$ from Table 5)

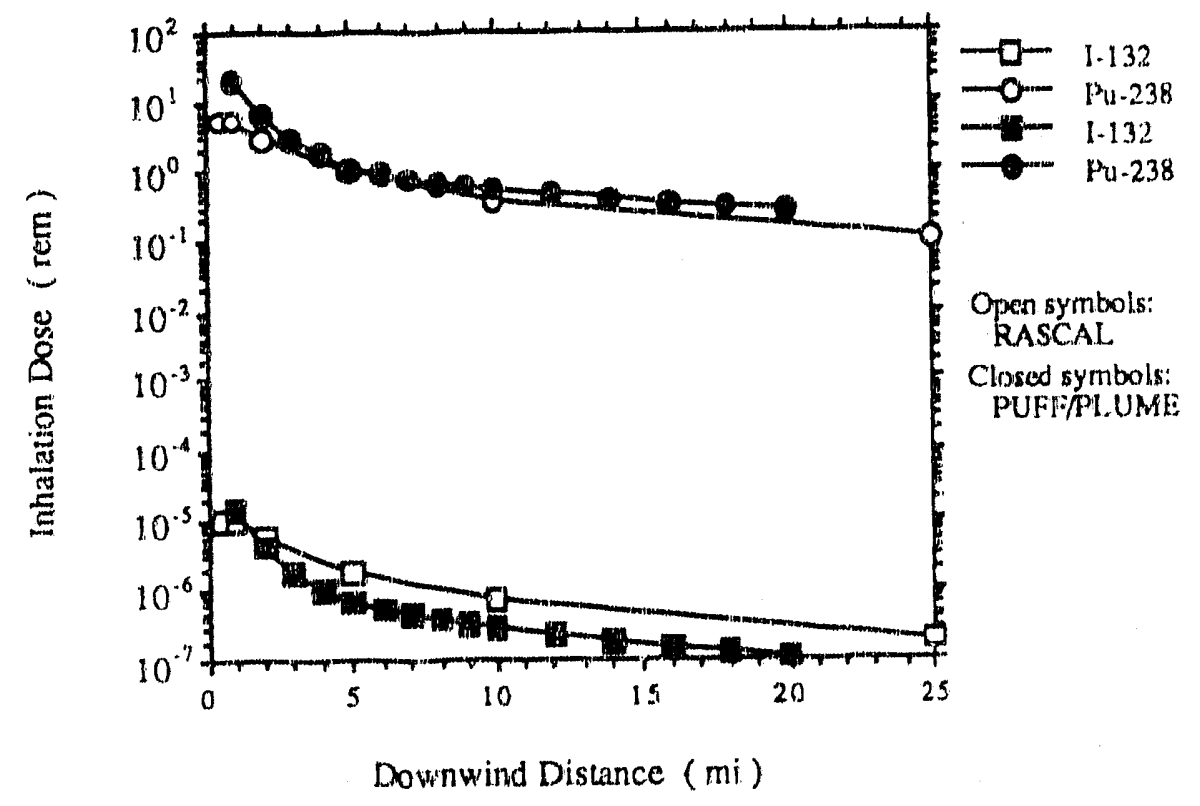

Figure 20. Inhalation dose calculated by 2 DPUF and RASCAL for a $15 \mathrm{~min}$ release with two isotopes (cases 1, 8 from Table 5) 


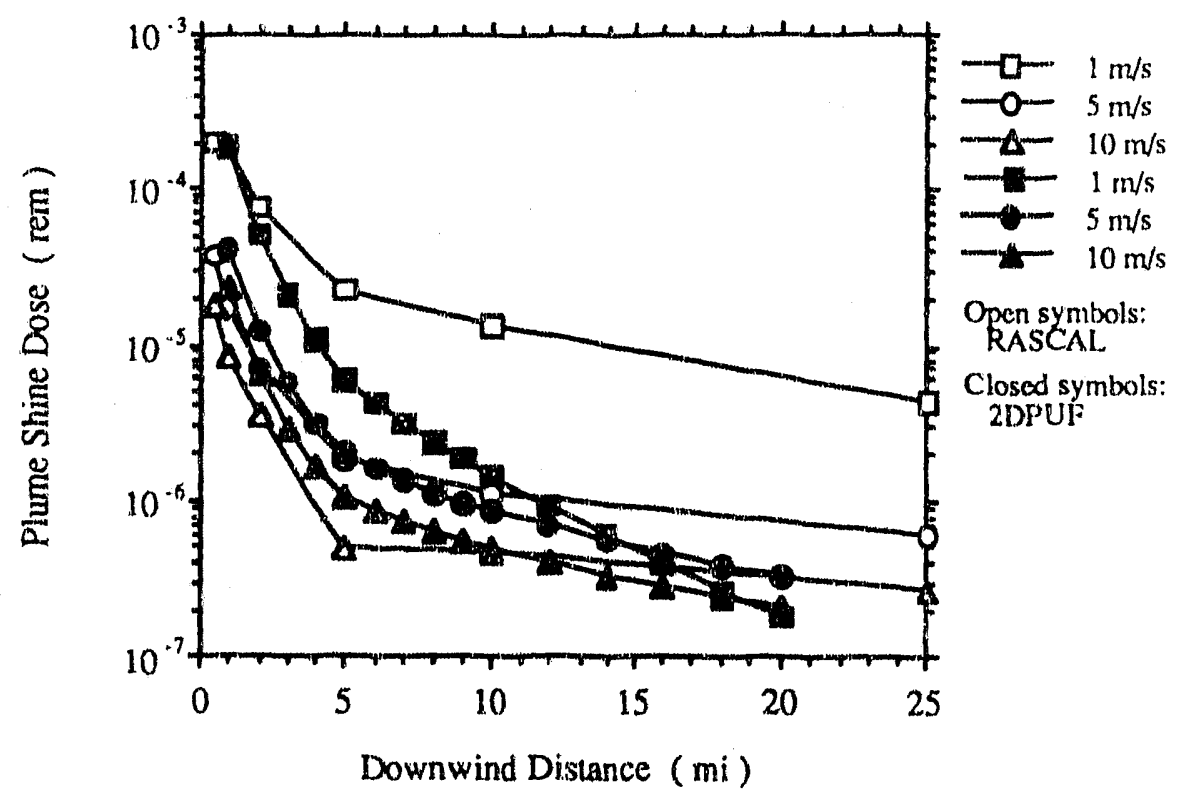

Figure 21. Cloud shine dose calculated by 2DPUF and RASCAL f $15 \mathrm{~min}$ release with various wind speeds (cases $1,2,3$ from Table 5 )

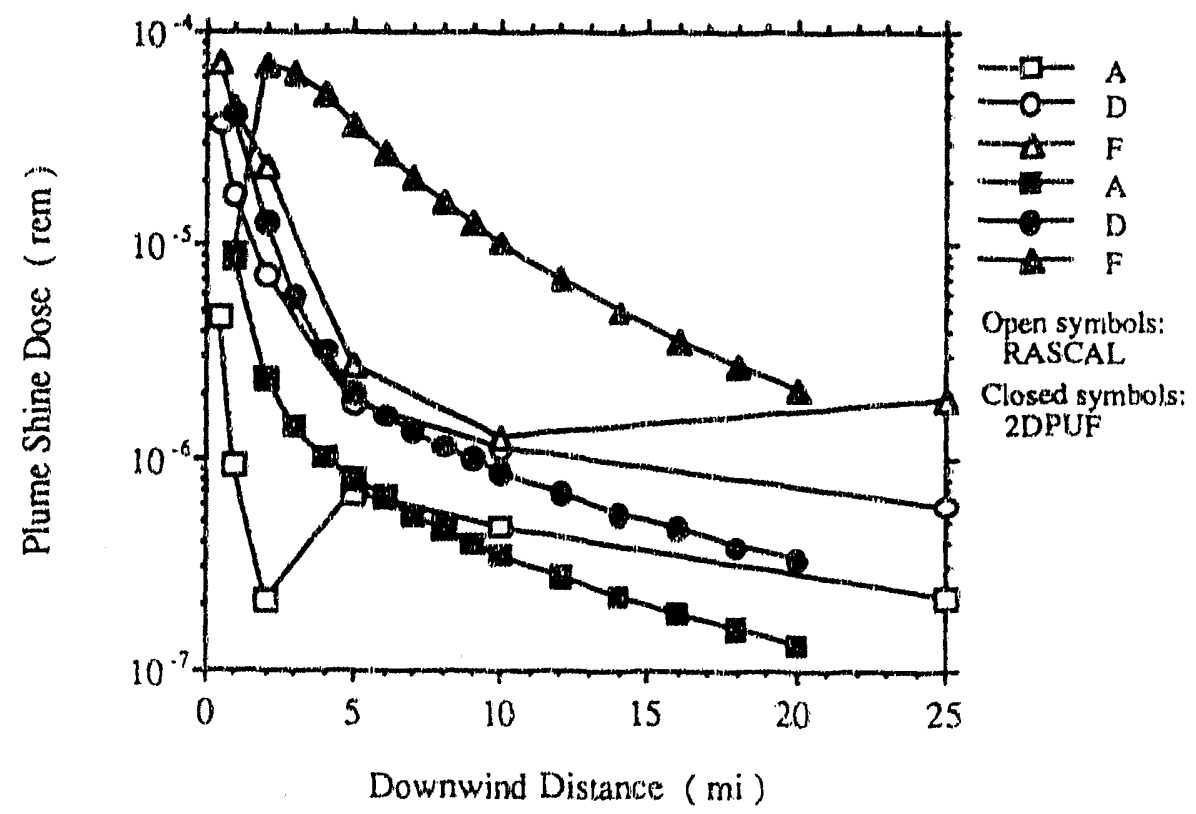

Figure 22. Cloud shine dose calculated by 2DPUF and RASCAL for a $15 \mathrm{~min}$ release with various atmospheric stabilities (cases $1,4,5$ from Table 5) 


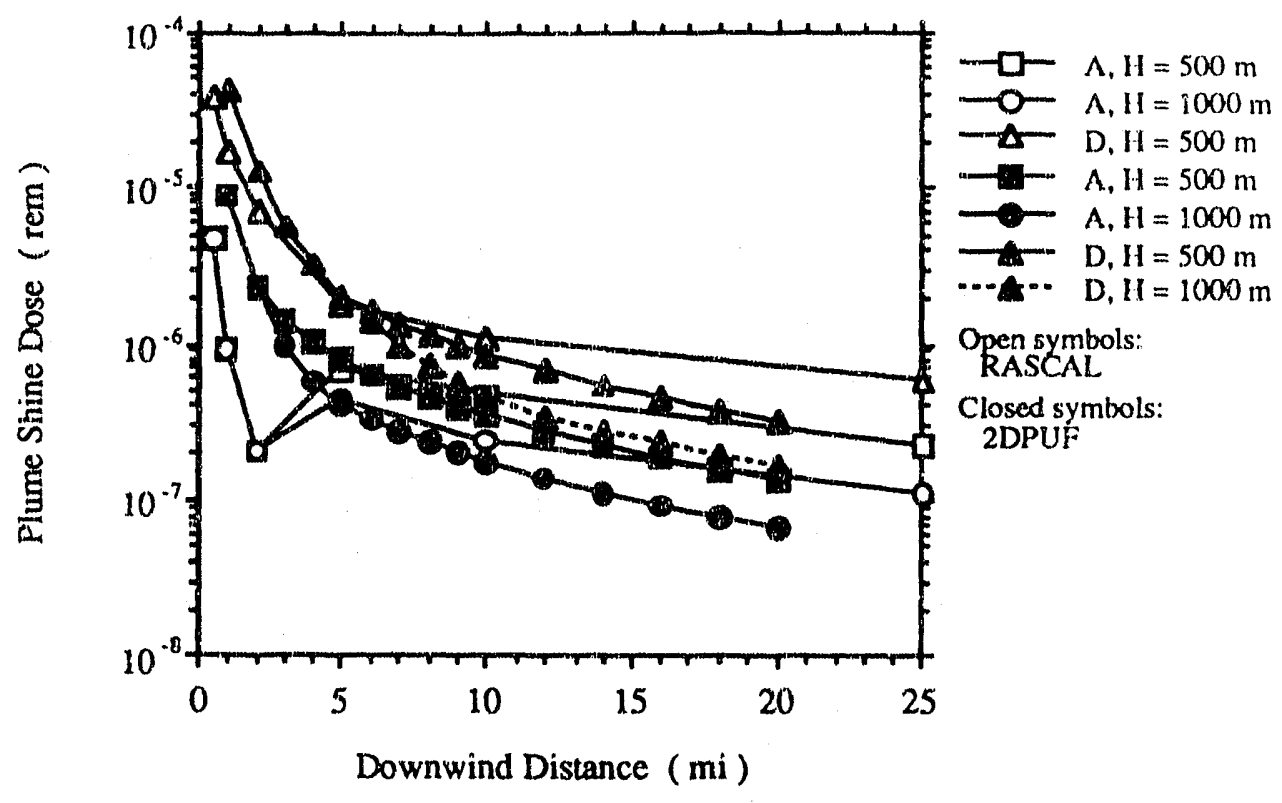

Figure 23. Cloud shine dose calculated by 2DPUF and RASCAL for a $15 \mathrm{~min}$ release with various boundary-layer depths (cases 1, 4, 6, 7 from Table 5)

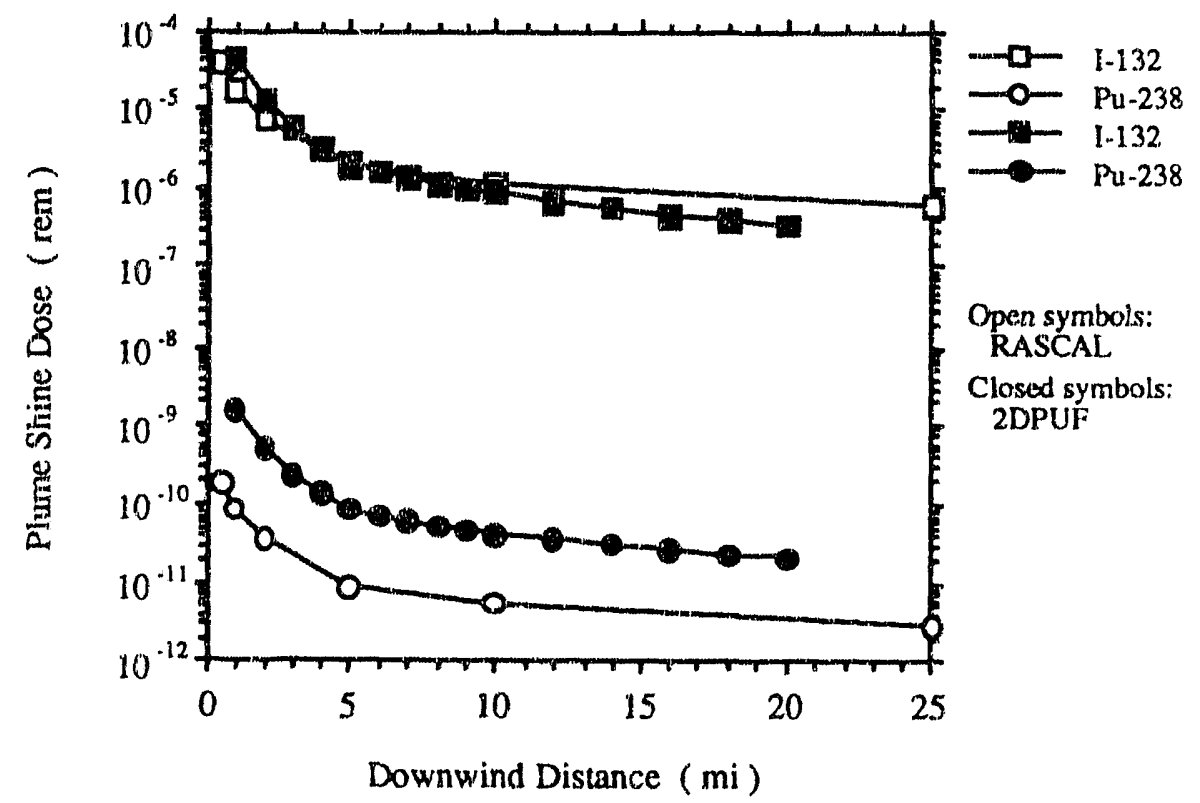

Figure 24. Cloud shine dose calculated by 2DPUF and RASCAL for a $15 \mathrm{~min}$ release with various isotopes (cases 1,8 from Table 5) 
Table 1. Comparison of the source term capabilities of the WIND System atmospheric models and RASCAL

Source Location:

\begin{tabular}{|c|c|}
\hline RASCAL & single source \\
\hline AREA EVACUATTON & single source from SRS production facility area \\
\hline PUFF/PLUME & $\begin{array}{l}\text { single source from SRS production facility area or location } \\
\text { specified by user }\end{array}$ \\
\hline 2DPUF & $\begin{array}{l}\text { single source from SRS production facility area or location } \\
\text { specified by user }\end{array}$ \\
\hline \multicolumn{2}{|l|}{ Release Height: } \\
\hline RASCAL & specified by user \\
\hline AREA EVACUATION & default value of $40 \mathrm{~m}$ \\
\hline PUFF/PLUME & default value of $61 \mathrm{~m}$ or specified by user \\
\hline 2DPUF & default value of $61 \mathrm{~m}$ or specified by user \\
\hline \multicolumn{2}{|l|}{ Emission Estimation: } \\
\hline RASCAL & $\begin{array}{l}\text { (1) release rate for single or multiple isotopes specified by } \\
\text { user, (2) gross reactor release rates with mix specified by user, } \\
\text { (3) gross reactor release rates with mix based on accident } \\
\text { conditions, (4) reactor accident condition based on core/release } \\
\text { pathway conditions, (5) reactor accident condition based on } \\
\text { WASH } 1400 \text { categories }\end{array}$ \\
\hline AREA EVACUATION & $\begin{array}{l}\text { release rate for single isotope specified by user with guidance } \\
\text { from stack monitors }\end{array}$ \\
\hline PUFF/PLUME & $\begin{array}{l}\text { release rate or release amount for single isotope specified by } \\
\text { user with guidance from stack monitors }\end{array}$ \\
\hline 2DPUF & $\begin{array}{l}\text { release amount for single or multiple isotopes specified by user } \\
\text { with guidance from stack monitors, or source term may be } \\
\text { accessed directly from REACTOR ACCDENT }\end{array}$ \\
\hline REACTOR ACCIDENT & $\begin{array}{l}\text { release amount based on estimated number of reactor } \\
\text { assemblies melted or real-time gross activity reading from } \\
\text { stack monitor in reactor stack }\end{array}$ \\
\hline \multicolumn{2}{|l|}{ Release Duration: } \\
\hline RASCAL & minimum of 10 min and a maximum of $22 \mathrm{hr}$ \\
\hline ARE 4 EVACUATION & $\begin{array}{l}\text { emission specified as a rate and a continuous duration is } \\
\text { assumed }\end{array}$ \\
\hline PUFF/PLUME & $\begin{array}{l}\text { for a "puff" emission, specified in total amount released } \\
\text { assuming a } 15 \text { min duration; for a "plume" emission, specified } \\
\text { as rate with no upper limit on release duration }\end{array}$ \\
\hline 2DPUF & minimum of $15 \mathrm{~min}$ and a maximum of $23 \mathrm{hr}$ \\
\hline REACTOR ACCIDENT & $2 \mathrm{hr}$ \\
\hline
\end{tabular}


Table 1 (cont'd)

\begin{tabular}{|c|c|}
\hline \multicolumn{2}{|l|}{ Initial Size of Release: } \\
\hline RASCAL & user unable to specify a value \\
\hline AREA EVACUATION & default value of $10 \mathrm{ft}$ (width of production facility stack) \\
\hline PUFF/PLUME & $\begin{array}{l}\text { default value of } 10 \mathrm{ft} \text { (width of production facility stack) or } \\
\text { specified by user }\end{array}$ \\
\hline 2DPUF & default value of $10 \mathrm{ft}$ (width of production facility stack) \\
\hline \multicolumn{2}{|l|}{ Radionuclides: } \\
\hline RASCAL & $\begin{array}{l}\text { Pu-238, Pu-239, Co-60, I-131, I-132, I-133, I-135, Ru-103, } \\
\text { Ru-106, Cs-137, Sr-90, I-134, H-3, P-32. S-35, Mn-54, Co- } \\
58, \mathrm{Sr}-89, \mathrm{Sr}-\mathrm{O} 1, \mathrm{Y}-91, \mathrm{Mo}-99, \mathrm{Tc}-99 \mathrm{~m}, \mathrm{Sb}-127, \mathrm{Sb}-129, \\
\mathrm{Te}-129 \mathrm{~m}, \mathrm{Te}-131 \mathrm{~m}, \mathrm{I}-125, \mathrm{Cs}-134, \mathrm{Cs}-136, \mathrm{Ba}-140, \mathrm{La}-140, \\
\mathrm{Ce}-144, \mathrm{Pm}-147, \mathrm{Eu}-155, \mathrm{Pi}-210, \mathrm{~Np}-239, \mathrm{Am}-241, \mathrm{Cm}- \\
242, \mathrm{Cm}-243, \mathrm{Cm}-244\end{array}$ \\
\hline AREA EVACUATION & $\begin{array}{l}\text { Pu-238, Pu-239, Co-60, I-131, I-132, I-133, I-135, Ru-103, } \\
\text { Ru-106, Cs-137, Sr-90, Cf-252. Cu-44, HTO, HT, I-130 }\end{array}$ \\
\hline PUFF/PLUME & $\begin{array}{l}\text { Pu-238, Pu-239, Co-60, I-131, I-132, I-133, I-135, Ru-103, } \\
\text { Ru-106, Cs-137, Sr-90, Cf-252, Cu-44, HTO, HT, I-130 }\end{array}$ \\
\hline 2DPUF & $\begin{array}{l}\text { Pu-238, Pu-239, Co-60, I-131, I-132, I-133, I-135, Ru-103, } \\
\text { Ru-106, Cs-137, Sr-90, I-134, Cf-252, Cu-44, HTO, HT, I- } \\
130\end{array}$ \\
\hline REACTOR ACCIDENT & $\mathrm{I}-131, \mathrm{I}-132, \mathrm{I}-133, \mathrm{I}-134, \mathrm{I}-135$ \\
\hline \multicolumn{2}{|l|}{ Noble Gases: } \\
\hline RASCAL & $\begin{array}{l}\mathrm{Kr}-85 \mathrm{~m}, \mathrm{Kr}-85, \mathrm{Kr}-87, \mathrm{Kr}-88, \mathrm{Xe}-131 \mathrm{~m}, \mathrm{Xe}-133 \mathrm{~m}, \mathrm{Xe}-133, \\
\mathrm{Xe}-135 \mathrm{~m}, \mathrm{Xe}-135\end{array}$ \\
\hline AREA EVACUATION & none \\
\hline PUFF/PLUME & $\begin{array}{l}\mathrm{Kr}-83 \mathrm{~m}, \mathrm{Kr}-85 \mathrm{~m}, \mathrm{Kr}-85, \mathrm{Kr}-87, \mathrm{Kr}-88, \mathrm{Xe}-131 \mathrm{~m}, \mathrm{Xe}- \\
133 \mathrm{~m}, \mathrm{Xe}-133, \mathrm{Xe}-135 \mathrm{~m}, \mathrm{Xe}-135\end{array}$ \\
\hline 2DPUF & $\begin{array}{l}\mathrm{Kr}-83 \mathrm{~m}, \mathrm{Kr}-85 \mathrm{~m}, \mathrm{Kr}-85, \mathrm{Kr}-87, \mathrm{Kr}-88, \mathrm{Xe}-131 \mathrm{~m}, \mathrm{Xe}- \\
133 \mathrm{~m}, \mathrm{Xe}-133, \mathrm{Xe}-135 \mathrm{~m}, \mathrm{Xe}-135\end{array}$ \\
\hline REACTOR ACCIDENT & $\begin{array}{l}\mathrm{Kr}-83 \mathrm{~m}, \mathrm{Kr}-85 \mathrm{~m}, \mathrm{Kr}-85, \mathrm{Kr}-87, \mathrm{Kr}-88, \mathrm{Xe}-131 \mathrm{~m}, \mathrm{Xe}- \\
133 \mathrm{~m}, \mathrm{Xe}-133, \mathrm{Xe}-135 \mathrm{~m}, \mathrm{Xe}-135\end{array}$ \\
\hline \multicolumn{2}{|l|}{ Chemicals: } \\
\hline RASCAL & none \\
\hline AREA EVACUATION & $\mathrm{Cl} 2, \mathrm{H} 2 \mathrm{~S}, \mathrm{SO} 2$ \\
\hline PUFF/PLUME & C12, $\mathrm{H} 2 \mathrm{~S}, \mathrm{SO} 2, \mathrm{SF} 6$, user-specified chemicals \\
\hline 2DPUF & none \\
\hline REACTOR ACCIDENT & none \\
\hline
\end{tabular}


Table 2. Comparison of the atmospheric transport and diffusion capabilities of the WIND System atmospheric models and RASCAL

\begin{tabular}{|c|c|}
\hline \multicolumn{2}{|l|}{ Advection Step: } \\
\hline RASCAL & $15 \mathrm{~min}$ \\
\hline AREA EVACUATION & $100 \mathrm{~m} /$ wind speed \\
\hline PUFF/PLUME & $1-5$ or $10 \mathrm{~min}$ \\
\hline 2DPUF & $\begin{array}{l}\text { variable in time, initial step is } 20 \mathrm{~s} \text { that increases in time } \\
\text { depending on puff growth }\end{array}$ \\
\hline \multicolumn{2}{|l|}{ Duration of Simulations: } \\
\hline RASCAL & $\begin{array}{l}\text { minimum of release duration and a maximum of } 24 \mathrm{hr} \\
\text { duration depends on whether } 10 \mathrm{mi} \text { or } 25 \mathrm{mi} \text { calculation is } \\
\text { chosen }\end{array}$ \\
\hline AREA EVACUATION & $(100 \mathrm{~m} /$ wind speed $) * 75$ \\
\hline PUFF/PLUME & depends on advection step and with speed \\
\hline 2DPUF & minimum of release duration $+4 \mathrm{hr}$ and a maximum of $23 \mathrm{hr}$ \\
\hline \multicolumn{2}{|l|}{ Diffusion Parameters: } \\
\hline RASCAL & Turner's Workbook \\
\hline AREA EVACUATION & Pasquill \\
\hline PUFF/PLUME & Pasquill, Briggs \\
\hline 2DPUF & Briggs \\
\hline \multicolumn{2}{|c|}{ Meteorological Conditions: } \\
\hline$\overline{\text { RASCAL }}$ & $\begin{array}{l}\text { entered manually (up to } 4 \text { records of data with times specified } \\
\text { by the user) }\end{array}$ \\
\hline AREA EVACUATION & $\begin{array}{l}\text { latest } 15 \mathrm{~min} \text { average (quality assured) from meteorological } \\
\text { tower adiacent to incident area }\end{array}$ \\
\hline PUFF/PLUME & $\begin{array}{l}\text { (1) latest } 15 \mathrm{~min} \text { average (quality assured) from meteorological } \\
\text { tower adjacent to incident area, (2) entered manually (up to } 12 \\
\text { records representing hours of data), (3) local forecast } \\
\text { automatically accessed, (4) canned data read in from a file }\end{array}$ \\
\hline 2DPUF & $\begin{array}{l}\text { (1) entered manually (up to } 23 \text { records representing hours of } \\
\text { data), (2) local forecast or regional data automatically accessed, } \\
\text { (3) archived meteorological data, (4) canned data read in from } \\
\text { a file }\end{array}$ \\
\hline \multicolumn{2}{|l|}{ Dry Deposition: } \\
\hline RASCAL & yes \\
\hline AREA EVACUATTON & no \\
\hline PUFF/PLUME & yes \\
\hline & \\
\hline
\end{tabular}


Table 2 (cont'd)

Wet Deposition:

\begin{tabular}{|l|l|}
\hline RASCAL & light $\left(<1 \mathrm{~mm} \mathrm{hr}^{-1}\right)$, moderate $\left(1-10 \mathrm{~mm} \mathrm{hr}^{-1}\right)$, or heavy $(>10$
\end{tabular}

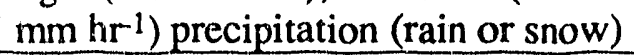

AREA EVACUATION none

\begin{tabular}{l|l}
\hline PUFF/PLUME & light $\left(1 \mathrm{~mm} \mathrm{hr}^{-1}\right)$ or heavy $\left(5 \mathrm{~mm} \mathrm{hr}^{-1}\right)$ precipitation (rain)
\end{tabular}

\begin{tabular}{|l|l|}
\hline 2DPUF & none \\
\hline
\end{tabular} 
Table 3. Comparison of the dose and consequence capabilities of the WIND System atmospheric models and RASCAL

Exposed Individual:

\begin{tabular}{|l|l|}
\hline RASCAL & Child, Adult \\
\hline AREA EVACUATION & Adult \\
\hline PUFF/PLUME & Child, Adult \\
\hline 2DPUF & Adult \\
\hline
\end{tabular}

Radiological Decay:

\begin{tabular}{|l|l|}
\hline RASCAL & yes \\
\hline AREA EVACUATION & yes \\
\hline PUFF/PLUME & yes \\
\hline 2DPUF & yes \\
\hline
\end{tabular}

Predicts External Exposure:

RASCAL

AREA EVACUATION

PUFF/PLUME

2DPUF

REACTOR ACCIDENT

yes, whole body cloud shine, whole body ground shine no

yes, whole body cloud shine for only iodines and noble gases, currently not used

yes, whole body cloud shine

yes, whole body cloud shine for only iodines and noble gases

Predicts Internal Exposure:

RASCAL

AREA EVACUATION

PUFF/PLUME

2DPUF

yes, organ specific for thyroid, lung, and bone yes

yes, organ specific for thyroid

yes

Predicts Total Exposure (External + Internal):

\begin{tabular}{|l|l|}
\hline RASCAL & yes \\
\hline AREA EVACUATION & no \\
\hline PUFF/PLUME & no \\
\hline 2DPUF & yes \\
\hline
\end{tabular}

Predicts Arrival Time:

\begin{tabular}{|l|l|}
\hline RASCAL & no \\
\hline
\end{tabular}

\begin{tabular}{|l|l}
\hline AREA EVACUATION & no \\
\hline
\end{tabular}

\begin{tabular}{|l|l}
\hline PUFF/PLUME & yes \\
\hline
\end{tabular}

\begin{tabular}{|l|l}
\hline 2DPUF & no \\
\hline
\end{tabular} 
Table 3 (cont'd)

Dose Factors:

RASCAL

based on NUREG/CR-1918 and NRPB-R162

AREA EVACUATION based on ICRP 30

PUFF/PLUME

based on ICRP 30

2DPUF

based on IRCP 30 
Table 4. Comparison of the operational characteristics of the WIND System atmospheric models and RASCAL

Hardcopy and Output File:

\begin{tabular}{|l|l|}
\hline RASCAL & tabular and graphical results specified by user through menu \\
\hline AREA EVACUATION & graphical results generated automatically \\
\hline PUFF/PLUME & tabular and graphical results generated automatically \\
\hline 2DPUF & tabular and graphical results generated automatically \\
\hline
\end{tabular}

Type of Tabular Results:

\begin{tabular}{|l|l|}
\hline RASCAL & $\begin{array}{l}\text { (1) inputs and assumptions, (2) computed source term, }(3) \\
\text { maximum doses at } 6 \text { downwind distances }(0.5,1.0,2.0,5.0, \\
10.0, \text { and } 25.0 \mathrm{mi})\end{array}$ \\
\hline AREA EVACUATION & inputs \\
\hline PUFF/PLUME & $\begin{array}{l}\text { (1) inputs, (2) centerline dose or concentration, dose at the } \\
\text { "puff" or "plume" width (2o from the centerline), and percent } \\
\text { reduction due to deposition at various downwind distances, (3) } \\
\text { total dose at site boundary }\end{array}$ \\
\hline 2DPUF & (1) inputs, (2) maximum doses at discrete radial distances \\
\hline
\end{tabular}

Type of Graphical Results:

\begin{tabular}{|l|l|}
\hline RASCAL & symbols, no plot if below minimum value \\
\hline AREA EVACUATION & contours overlaid on background map \\
\hline PUFF/PLUME & $\begin{array}{l}\text { circles of radius 2o at each time step overlaid on background } \\
\text { map }\end{array}$ \\
\hline 2DPUF & contours overlaid on background map \\
\hline
\end{tabular}

Domain for Graphical Results:

\begin{tabular}{|l|l|}
\hline RASCAL & $\begin{array}{l}\text { results } 0 \text { - } 2 \text { mi from plant, or results greater than 2 mi from } \\
\text { plant }\end{array}$ \\
\hline AREA EVACUATION & $\begin{array}{l}\text { results within 4 } \mathrm{km} \text { of release location } \\
\text { local results within } 30 \mathrm{~km} \text { of release location, choice of } 3 \\
\text { regional results encompassing southeast U. } \text {. }\end{array}$ \\
\hline PUFF/PLUME & $\begin{array}{l}\text { local results within } 30 \mathrm{~km} \text { of release location, regional results } \\
\text { encompassing South Carolina and Georgia }\end{array}$ \\
\hline Background Maps: & \multicolumn{1}{|l|}{} \\
\hline RASCAL & concentric circles up to 25 mi radius \\
\hline AREA EVACUATION & SRS production facilities, roads, railroads, streams \\
\hline PUFF/PLUME & $\begin{array}{l}\text { SRS production facilities, roads, plant boundary, surrounding } \\
\text { cities, state boundaries }\end{array}$ \\
\hline 2DPUF & $\begin{array}{l}\text { SRS production facilities, roads, plant boundary, surrounding } \\
\text { cities, state boundaries }\end{array}$ \\
\hline
\end{tabular}


Table 4 (cont'd)

Computer System:

\begin{tabular}{|l|l|}
\hline RASCAL & $\begin{array}{l}\text { IBM compatible personal computer, 286 or 386 CPU, math } \\
\text { coprocessor }\end{array}$ \\
\hline AREA EVACUATION & $\begin{array}{l}\text { VAX 8550 mainframe and microvax linked to SRS } \\
\text { meteorological database }\end{array}$ \\
\hline PUFF/PLUME & $\begin{array}{l}\text { VAX 8550 mainframe and microvax linked to SRS and NWS } \\
\text { meteorological database }\end{array}$ \\
\hline 2DPUF & $\begin{array}{l}\text { VAX 8550 mainframe and microvax linked to SRS and NWS } \\
\text { meteorological database }\end{array}$ \\
\hline Design: & \multicolumn{2}{|l}{} \\
\hline RASCAL & menu-driven, generic \\
\hline AREAEVACUATION & line prompt, SRS site-specific \\
\hline PUFF/PLUME & line prompt, SRS site-specific \\
\hline 2DPUF & line prompt, SRS site-specific \\
\hline REACTOR ACCIDENT & menu-driven, SRS site-specific \\
\hline
\end{tabular}


Table 5. Input parameters for the WIND System atmospheric models and RASCAL

\begin{tabular}{|c|c|c|c|c|c|c|c|}
\hline Case & Specie & $\begin{array}{c}\text { Boundary-Layer } \\
\text { Depth }\end{array}$ & $\begin{array}{l}\text { Wind } \\
\text { Speed }\end{array}$ & $\sigma_{a}$ & $\sigma_{\mathrm{e}}$ & Stability & Deposition \\
\hline 1 & $\mathrm{I}-132$ & $500 \mathrm{~m}$ & $5 \mathrm{~m} / \mathrm{s}$ & 12.5 & 8.74 & D & none \\
\hline 2 & $\mathrm{I}-132$ & $500 \mathrm{~m}$ & $1 \mathrm{~m} / \mathrm{s}$ & 12.5 & 8.74 & D & none \\
\hline 3 & $\mathrm{I}-132$ & $500 \mathrm{~m}$ & $10 \mathrm{~m} / \mathrm{s}$ & 12.5 & 8.74 & $\mathrm{D}$ & none \\
\hline 4 & $\mathrm{I}-132$ & $500 \mathrm{~m}$ & $5 \mathrm{~m} / \mathrm{s}$ & 30.0 & 20.98 & $\mathrm{~A}$ & none \\
\hline 5 & $\mathrm{I}-132$ & $500 \mathrm{~m}$ & $5 \mathrm{~m} / \mathrm{s}$ & 2.5 & 1.74 & $\bar{F}$ & none \\
\hline 6 & $\mathrm{I}-132$ & $1000 \mathrm{~m}$ & $5 \mathrm{~m} / \mathrm{s}$ & 30.0 & 20.98 & A & none \\
\hline 7 & $\mathrm{I}-132$ & $1000 \mathrm{~m}$ & $5 \mathrm{~m} / \mathrm{s}$ & 12.5 & 8.74 & D & none \\
\hline 8 & $\overline{\mathrm{Pu}-238}$ & $500 \mathrm{~m}$ & $5 \mathrm{~m} / \mathrm{s}$ & 12.5 & 8.74 & $\bar{D}$ & none \\
\hline 9 & I-132 & $500 \mathrm{~m}$ & $1 \mathrm{~m} / \mathrm{s}$ & 30.0 & 20.98 & $\bar{A}$ & none \\
\hline 10 & $1-132$ & $500 \mathrm{~m}$ & $1 \mathrm{~m} / \mathrm{s}$ & 2.5 & 1.74 & F & none \\
\hline 11 & I-132 & $500 \mathrm{~m}$ & $5 \mathrm{~m} / \mathrm{s}$ & 12.5 & 8.74 & $\mathrm{D}$ & dry \\
\hline 12 & $\mathrm{I}-132$ & $500 \mathrm{~m}$ & $5 \mathrm{~m} / \mathrm{s}$ & 12.5 & 8.74 & $\mathrm{D}$ & wet, light \\
\hline 13 & $1-132$ & $500 \mathrm{~m}$ & $5 \mathrm{~m} / \mathrm{s}$ & 12.5 & 8.74 & $\mathrm{D}$ & wet, moderate \\
\hline 14 & $I-132$ & $500 \mathrm{~m}$ & $5 \mathrm{~m} / \mathrm{s}$ & 12.5 & 8.74 & $\mathrm{D}$ & wet, heavy \\
\hline 15 & $1-132$ & $500 \mathrm{~m}$ & $\begin{array}{c}1.8 \mathrm{~m} / \mathrm{s} \\
\text { (hour 1), } \\
3.1 \mathrm{~m} / \mathrm{s} \\
\text { (hour 2), } \\
4.4 \mathrm{~m} / \mathrm{s} \\
\text { (hour 3) }\end{array}$ & 12.5 & 8.74 & $\mathbf{D}$ & none \\
\hline
\end{tabular}

Table 6. Cases that were employed by each of the WIND System atmospheric models and RASCAL

\begin{tabular}{|l|c|c|}
\hline \multicolumn{1}{|c|}{ Model } & Mode of Operation & Cases \\
\hline RASCAL & "plume" & $1-10,12-14$ \\
\hline RASCAL & "puff" & $1-10,12-15$ \\
\hline AREA EVACUATION & "plume" & $1-8$ \\
\hline PUFF/PLUME & "plume" & $1-12,14$ \\
\hline PUFF/PLUME & "puff" & $1-12,14-15$ \\
\hline 2DPUF & "puff" & $1-8$ \\
\hline
\end{tabular}


Table 7. Comparison of the dose values predicted by RASCAL to the results of the WIND System atmospheric models at selected downwind distances

\begin{tabular}{|r|r|r|r|r|}
\hline Downwind Distance (mi) & \multicolumn{5}{|c|}{ \% of the results within a factor } \\
\cline { 2 - 5 } & $<2$ & $2-4$ & $4-10$ & $>10$ \\
\hline 0.5 & 78 & 16 & 2 & 4 \\
\hline 1.0 & 78 & 14 & 6 & 2 \\
\hline 2.0 & 72 & 22 & 4 & 2 \\
\hline 5.0 & 76 & 18 & 4 & 2 \\
\hline 10.0 & 68 & 16 & 16 & 0 \\
\hline 25.0 & 50 & 28 & 18 & 4 \\
\hline average & 70.3 & 19.0 & 8.3 & 2.3 \\
\hline
\end{tabular}

Table 8. Comparison of the dose values predicted by RASCAL to the results of the individual WIND System atmospheric models

\begin{tabular}{|l|c|r|r|r|r|}
\hline \multirow{2}{*}{ Model } & Mode of Operation & \multicolumn{3}{c|}{ \% of the results within a factor } \\
\cline { 3 - 6 } & & $<2$ & $2-4$ & $4-10$ & $>10$ \\
\hline AREA EVACUATION & "plume", inhalation dose & 77 & 17 & 4 & 2 \\
\hline PUFF/PLUME & "plume", inhalation dose & 86 & 10 & 4 & 0 \\
\hline PUFF/PLUME & "puff", inhalation dose & 76 & 19 & 5 & 0 \\
\hline 2DPUF & "puff", inhalation dose & 52 & 36 & 10 & 2 \\
\hline 2DPUF & "puff", cloud shine dose & 48 & 19 & 23 & 10 \\
\hline
\end{tabular}


Table 9. Ground centerline inhalation and cloud shine dose at selected downwind distances predicted by RASCAL using the input parameters specified in Table 5

Inhalation Dose (rem), "Plume" Calculations:

\begin{tabular}{|r|r|r|r|r|r|r|}
\hline \multirow{2}{*}{ Case } & \multicolumn{7}{|c|}{ Downwind Distance (mi) } \\
\cline { 2 - 7 } & 0.5 & 1.0 & 2.0 & 5.0 & 10.0 & 25.0 \\
\hline 1 & $4.2 \mathrm{e}-5$ & $3.9 \mathrm{e}-5$ & $2.3 \mathrm{e}-5$ & $7.5 \mathrm{e}-6$ & $3.0 \mathrm{e}-6$ & $7.3 \mathrm{e}-7$ \\
\hline 2 & $2.3 \mathrm{e}-4$ & $2.2 \mathrm{e}-4$ & $1.2 \mathrm{e}-4$ & $4.1 \mathrm{e}-5$ & $1.6 \mathrm{e}-5$ & $6.4 \mathrm{e}-7$ \\
\hline 3 & $2.1 \mathrm{e}-5$ & $2.0 \mathrm{e}-5$ & $1.1 \mathrm{e}-5$ & $2.1 \mathrm{e}-6$ & $1.5 \mathrm{e}-6$ & $4.1 \mathrm{e}-7$ \\
\hline 4 & $1.0 \mathrm{e}-5$ & $4.7 \mathrm{e}-6$ & $2.6 \mathrm{e}-6$ & $9.9 \mathrm{e}-7$ & $4.9 \mathrm{e}-7$ & $2.1 \mathrm{e}-7$ \\
\hline 5 & $3.5 \mathrm{e}-6$ & $1.3 \mathrm{e}-5$ & $2.2 \mathrm{e}-5$ & $2.5 \mathrm{e}-5$ & $1.1 \mathrm{e}-5$ & $4.3 \mathrm{e}-6$ \\
\hline 6 & $9.9 \mathrm{e}-6$ & $2.4 \mathrm{e}-6$ & $1.3 \mathrm{e}-6$ & $4.9 \mathrm{e}-7$ & $2.5 \mathrm{e}-7$ & $1.0 \mathrm{e}-7$ \\
\hline 7 & $4.2 \mathrm{e}-5$ & $3.9 \mathrm{e}-5$ & $2.3 \mathrm{e}-5$ & $7.5 \mathrm{e}-6$ & $3.0 \mathrm{e}-6$ & $7.2 \mathrm{e}-7$ \\
\hline 8 & $2.1 \mathrm{e}+1$ & $2.0 \mathrm{e}+1$ & $1.1 \mathrm{e}+1$ & $3.7 \mathrm{e}+0$ & $1.5 \mathrm{e}+0$ & $3.6 \mathrm{e}-1$ \\
\hline 9 & $5.5 \mathrm{e}-5$ & $2.6 \mathrm{e}-5$ & $1.4 \mathrm{e}-5$ & $5.7 \mathrm{e}-6$ & $3.1 \mathrm{e}-6$ & $4.2 \mathrm{e}-7$ \\
\hline 10 & $1.9 \mathrm{e}-5$ & $7.4 \mathrm{e}-5$ & $1.2 \mathrm{e}-4$ & $9.8 \mathrm{e}-5$ & $6.0 \mathrm{e}-5$ & $8.5 \mathrm{e}-7$ \\
\hline 12 & $4.2 \mathrm{e}-5$ & $3.9 \mathrm{e}-5$ & $2.3 \mathrm{e}-5$ & $5.5 \mathrm{e}-6$ & $1.5 \mathrm{e}-6$ & $1.3 \mathrm{e}-7$ \\
\hline 13 & $4.2 \mathrm{e}-5$ & $3.9 \mathrm{e}-5$ & $2.3 \mathrm{e}-5$ & $3.1 \mathrm{e}-6$ & $4.8 \mathrm{e}-7$ & $6.3 \mathrm{e}-9$ \\
\hline 14 & $4.2 \mathrm{e}-5$ & $3.9 \mathrm{e}-5$ & $2.3 \mathrm{e}-5$ & $1.5 \mathrm{e}-6$ & $1.1 \mathrm{e}-7$ & $1.3 \mathrm{e}-10$ \\
\hline
\end{tabular}

Inhalation Dose (rem), "Puff" Calculations:

\begin{tabular}{|r|r|r|r|r|r|r|}
\hline \multirow{2}{*}{ Case } & \multicolumn{7}{|c|}{ Downwind Distance (mi) } \\
\cline { 2 - 7 } & 0.5 & 1.0 & 2.0 & 5.0 & 10.0 & \multicolumn{1}{c|}{25.0} \\
\hline 1 & $1.0 \mathrm{e}-5$ & $9.8 \mathrm{e}-6$ & $5.6 \mathrm{e}-6$ & $1.9 \mathrm{e}-6$ & $7.4 \mathrm{e}-7$ & $2.0 \mathrm{e}-7$ \\
\hline 2 & $5.7 \mathrm{e}-5$ & $5.4 \mathrm{e}-5$ & $3.1 \mathrm{e}-5$ & $1.0 \mathrm{e}-5$ & $4.1 \mathrm{e}-6$ & $3.2 \mathrm{e}-7$ \\
\hline 3 & $5.2 \mathrm{e}-6$ & $4.9 \mathrm{e}-6$ & $2.8 \mathrm{e}-6$ & $5.3 \mathrm{e}-7$ & $3.7 \mathrm{e}-7$ & $1.0 \mathrm{e}-7$ \\
\hline 4 & $2.5 \mathrm{e}-6$ & $1.2 \mathrm{e}-6$ & $6.4 \mathrm{e}-7$ & $2.5 \mathrm{e}-7$ & $1.2 \mathrm{e}-7$ & $6.0 \mathrm{e}-8$ \\
\hline 5 & $8.7 \mathrm{e}-7$ & $3.4 \mathrm{e}-6$ & $5.5 \mathrm{e}-6$ & $6.1 \mathrm{e}-6$ & $2.8 \mathrm{e}-6$ & $1.2 \mathrm{e}-6$ \\
\hline 6 & $2.5 \mathrm{e}-6$ & $6.0 \mathrm{e}-7$ & $3.2 \mathrm{e}-7$ & $1.2 \mathrm{e}-7$ & $6.2 \mathrm{e}-8$ & $3.0 \mathrm{e}-8$ \\
\hline 7 & $1.0 \mathrm{e}-5$ & $9.8 \mathrm{e}-6$ & $5.6 \mathrm{e}-6$ & $1.9 \mathrm{e}-6$ & $7.4 \mathrm{e}-7$ & $2.0 \mathrm{e}-7$ \\
\hline 8 & $5.2 \mathrm{e}+0$ & $4.9 \mathrm{e}+0$ & $2.8 \mathrm{e}+0$ & $9.3 \mathrm{e}-1$ & $3.6 \mathrm{e}-1$ & $1.0 \mathrm{e}-1$ \\
\hline 9 & $1.4 \mathrm{e}-5$ & $6.5 \mathrm{e}-6$ & $3.5 \mathrm{e}-6$ & $1.4 \mathrm{e}-6$ & $7.6 \mathrm{e}-7$ & $1.4 \mathrm{e}-7$ \\
\hline 10 & $4.8 \mathrm{e}-6$ & $1.8 \mathrm{e}-5$ & $3.0 \mathrm{e}-5$ & $2.4 \mathrm{e}-5$ & $1.5 \mathrm{e}-5$ & $7.2 \mathrm{e}-7$ \\
\hline 12 & $1.0 \mathrm{e}-5$ & $9.8 \mathrm{e}-6$ & $5.6 \mathrm{e}-6$ & $1.4 \mathrm{e}-6$ & $3.8 \mathrm{e}-7$ & $3.6 \mathrm{e}-8$ \\
\hline 13 & $1.0 \mathrm{e}-5$ & $9.8 \mathrm{e}-6$ & $5.6 \mathrm{e}-6$ & $7.7 \mathrm{e}-7$ & $1.2 \mathrm{e}-7$ & $1.7 \mathrm{e}-9$ \\
\hline 14 & $1.0 \mathrm{e}-5$ & $9.8 \mathrm{e}-6$ & $5.6 \mathrm{e}-6$ & $3.7 \mathrm{e}-7$ & $2.7 \mathrm{e}-8$ & $3.6 \mathrm{e}-11$ \\
\hline 15 & $2.9 \mathrm{e}-5$ & $2.7 \mathrm{e}-5$ & $1.5 \mathrm{e}-5$ & $2.9 \mathrm{e}-6$ & $1.1 \mathrm{e}-6$ & $4.5 \mathrm{e}-8$ \\
\hline
\end{tabular}


Table 9 (cont'd)

Cloud Shine Dose (rem), "Plume" Calculations:

\begin{tabular}{|r|r|r|r|r|r|r|}
\hline Case & \multicolumn{7}{|c|}{ Downwind Distance (mi) } \\
\cline { 2 - 7 } & \multicolumn{1}{|c|}{0.5} & 1.0 & 2.0 & 5.0 & 10.0 & 25.0 \\
\hline 1 & $3.7 \mathrm{e}-5$ & $1.7 \mathrm{e}-5$ & $7.1 \mathrm{e}-6$ & $1.8 \mathrm{e}-6$ & $1.1 \mathrm{e}-6$ & $5.9 \mathrm{e}-7$ \\
\hline 2 & $2.0 \mathrm{e}-4$ & $1.8 \mathrm{e}-4$ & $7.6 \mathrm{e}-5$ & $2.2 \mathrm{e}-5$ & $1.3 \mathrm{e}-5$ & $4.4 \mathrm{e}-6$ \\
\hline 3 & $1.8 \mathrm{e}-5$ & $8.6 \mathrm{e}-6$ & $3.5 \mathrm{e}-6$ & $4.9 \mathrm{e}-7$ & $4.7 \mathrm{e}-7$ & $2.6 \mathrm{e}-7$ \\
\hline 4 & $4.6 \mathrm{e}-6$ & $9.1 \mathrm{e}-7$ & $2.1 \mathrm{e}-7$ & $6.7 \mathrm{e}-7$ & $4.7 \mathrm{e}-7$ & $2.2 \mathrm{e}-7$ \\
\hline 5 & $7.2 \mathrm{e}-5$ & $4.3 \mathrm{e}-5$ & $2.3 \mathrm{e}-5$ & $2.7 \mathrm{e}-6$ & $1.2 \mathrm{e}-6$ & $1.9 \mathrm{e}-6$ \\
\hline 6 & $4.6 \mathrm{e}-6$ & $9.1 \mathrm{e}-7$ & $2.1 \mathrm{e}-7$ & $4.4 \mathrm{e}-7$ & $2.4 \mathrm{e}-7$ & $1.1 \mathrm{e}-7$ \\
\hline 7 & $3.7 \mathrm{e}-5$ & $1.7 \mathrm{e}-5$ & $7.1 \mathrm{e}-6$ & $1.8 \mathrm{e}-6$ & $1.1 \mathrm{e}-6$ & $5.9 \mathrm{e}-7$ \\
\hline 8 & $1.8 \mathrm{e}-10$ & $8.3 \mathrm{e}-11$ & $3.4 \mathrm{e}-11$ & $8.5 \mathrm{e}-12$ & $5.4 \mathrm{e}-12$ & $2.9 \mathrm{e}-12$ \\
\hline
\end{tabular}


Table 10. Ground centerline inhalation dose at selected downwind distances predicted by AREA EVACUATION using the input parameters specified in Table 5

Inhalation Dose (rem), "Plume" Calculations:

\begin{tabular}{|r|c|c|c|c|c|c|}
\hline Case & \multicolumn{7}{|c|}{ Downwind Distance (mi) } \\
\cline { 2 - 7 } & 0.5 & 1.0 & 2.0 & 5.0 & 10.0 & 25.0 \\
\hline 1 & $2.870 \mathrm{e}-5$ & $2.361 \mathrm{e}-5$ & $1.201 \mathrm{e}-5$ & $3.781 \mathrm{e}-6$ & $1.422 \mathrm{e}-6$ & $3.340 \mathrm{e}-7$ \\
\hline 2 & $1.360 \mathrm{e}-4$ & $1.060 \mathrm{e}-4$ & $4.835 \mathrm{e}-5$ & $1.100 \mathrm{e}-5$ & $2.047 \mathrm{e}-6$ & $1.115 \mathrm{e}-7$ \\
\hline 3 & $1.445 \mathrm{e}-5$ & $1.197 \mathrm{e}-5$ & $6.168 \mathrm{e}-6$ & $2.023 \mathrm{e}-6$ & $8.139 \mathrm{e}-7$ & $2.342 \mathrm{e}-7$ \\
\hline 4 & $1.071 \mathrm{e}-5$ & $3.049 \mathrm{e}-6$ & $1.351 \mathrm{e}-6$ & $5.888 \mathrm{e}-7$ & $3.010 \mathrm{e}-7$ & $1.092 \mathrm{e}-7$ \\
\hline 5 & $4.893 \mathrm{e}-8$ & $6.393 \mathrm{e}-6$ & $2.456 \mathrm{e}-5$ & $2.250 \mathrm{e}-5$ & $1.331 \mathrm{e}-5$ & $5.109 \mathrm{e}-6$ \\
\hline 6 & $1.071 \mathrm{e}-5$ & $3.049 \mathrm{e}-6$ & $8.417 \mathrm{e}-7$ & $2.970 \mathrm{e}-7$ & $1.518 \mathrm{e}-7$ & $5.507 \mathrm{e}-8$ \\
\hline 7 & $2.870 \mathrm{e}-5$ & $2.361 \mathrm{e}-5$ & $1.201 \mathrm{e}-5$ & $3.781 \mathrm{e}-6$ & $1.422 \mathrm{e}-6$ & $3.340 \mathrm{e}-7$ \\
\hline 8 & $4.041 \mathrm{e}+1$ & $3.370 \mathrm{e}+1$ & $1.760 \mathrm{e}+1$ & $6.012 \mathrm{e}+0$ & $2.588 \mathrm{e}+0$ & $9.127 \mathrm{e}-1$ \\
\hline
\end{tabular}


Table 11. Ground centerline inhalation dose at selected downwind distances predicted by PUFF/PLUME using the input parameters specified in Table 5

Inhalation Dose (rem), "Plume" Calculations:

\begin{tabular}{|r|r|r|r|r|r|r|}
\hline Case & \multicolumn{7}{|c|}{ Downwind Distance (mi) } \\
\cline { 2 - 7 } & 0.37 & 1.12 & 1.87 & 3.73 & 5.97 & 8.21 \\
\hline 1 & $3.52 \mathrm{e}-5$ & $2.27 \mathrm{e}-5$ & $1.41 \mathrm{e}-5$ & $6.34 \mathrm{e}-6$ & $3.45 \mathrm{e}-6$ & $2.37 \mathrm{e}-6$ \\
\hline 3 & $1.77 \mathrm{e}-5$ & $1.15 \mathrm{e}-5$ & $7.22 \mathrm{e}-6$ & $3.33 \mathrm{e}-6$ & $1.87 \mathrm{e}-6$ & $1.32 \mathrm{e}-6$ \\
\hline 4 & $1.62 \mathrm{e}-5$ & $2.63 \mathrm{e}-6$ & $1.64 \mathrm{e}-6$ & $9.24 \mathrm{e}-7$ & $6.06 \mathrm{e}-7$ & $4.77 \mathrm{e}-7$ \\
\hline 5 & $3.54 \mathrm{e}-6$ & $3.51 \mathrm{e}-5$ & $4.37 \mathrm{e}-5$ & $3.59 \mathrm{e}-5$ & $2.61 \mathrm{e}-5$ & $2.13 \mathrm{e}-5$ \\
\hline 6 & $1.62 \mathrm{e}-5$ & $2.63 \mathrm{e}-6$ & $1.08 \mathrm{e}-6$ & $4.66 \mathrm{e}-7$ & $3.06 \mathrm{e}-7$ & $2.40 \mathrm{e}-7$ \\
\hline 7 & $3.52 \mathrm{e}-5$ & $2.27 \mathrm{e}-5$ & $1.41 \mathrm{e}-5$ & $6.34 \mathrm{e}-6$ & $3.45 \mathrm{e}-6$ & $2.37 \mathrm{e}-6$ \\
\hline 8 & $4.94 \mathrm{e}+1$ & $3.26 \mathrm{e}+1$ & $2.06 \mathrm{e}+1$ & $9.74 \mathrm{e}+0$ & $5.63 \mathrm{e}+0$ & $4.11 \mathrm{e}+0$ \\
\hline 9 & $8.15 \mathrm{e}-5$ & $1.22 \mathrm{e}-5$ & $6.93 \mathrm{e}-6$ & $3.19 \mathrm{e}-6$ & $1.64 \mathrm{e}-6$ & $1.01 \mathrm{e}-6$ \\
\hline 10 & $1.63 \mathrm{e}-5$ & $1.56 \mathrm{e}-4$ & $1.82 \mathrm{e}-4$ & $1.23 \mathrm{e}-4$ & $7.05 \mathrm{e}-5$ & $4.49 \mathrm{e}-5$ \\
\hline 11 & $3.56 \mathrm{e}-5$ & $2.29 \mathrm{e}-5$ & $1.42 \mathrm{e}-5$ & $6.29 \mathrm{e}-6$ & $3.33 \mathrm{e}-6$ & $2.2 \mathrm{e}-6$ \\
\hline 12 & $3.52 \mathrm{e}-5$ & $2.23 \mathrm{e}-5$ & $1.35 \mathrm{e}-5$ & $5.68 \mathrm{e}-6$ & $2.82 \mathrm{e}-6$ & $1.76 \mathrm{e}-6$ \\
\hline 14 & $3.47 \mathrm{e}-5$ & $2.12 \mathrm{e}-5$ & $1.24 \mathrm{e}-5$ & $4.82 \mathrm{e}-6$ & $2.17 \mathrm{e}-6$ & $1.22 \mathrm{e}-6$ \\
\hline
\end{tabular}

\begin{tabular}{|r|r|r|r|r|r|r|}
\hline Case & \multicolumn{7}{|c|}{ Downwind Distance (mi) } \\
\cline { 2 - 7 } & 10.45 & 12.69 & 14.93 & 17.17 & 19.41 & 21.65 \\
\hline 1 & $1.78 \mathrm{e}-6$ & $1.39 \mathrm{e}-6$ & $1.12 \mathrm{e}-6$ & $9.22 \mathrm{e}-7$ & $7.71 \mathrm{e}-7$ & $6.53 \mathrm{e}-7$ \\
\hline 3 & $1.02 \mathrm{e}-6$ & $8.25 \mathrm{e}-7$ & $6.85 \mathrm{e}-7$ & $5.81 \mathrm{e}-7$ & $5.01 \mathrm{e}-7$ & $4.38 \mathrm{e}-7$ \\
\hline 4 & $3.98 \mathrm{e}-7$ & $3.40 \mathrm{e}-7$ & $2.95 \mathrm{e}-7$ & $2.59 \mathrm{e}-7$ & $2.29 \mathrm{e}-7$ & $2.05 \mathrm{e}-7$ \\
\hline 5 & $1.81 \mathrm{e}-5$ & $1.56 \mathrm{e}-5$ & $1.36 \mathrm{e}-5$ & $1.20 \mathrm{e}-5$ & $1.07 \mathrm{e}-5$ & $9.54 \mathrm{e}-6$ \\
\hline 6 & $2.01 \mathrm{e}-7$ & $1.72 \mathrm{e}-7$ & $1.49 \mathrm{e}-7$ & $1.31 \mathrm{e}-7$ & $1.16 \mathrm{e}-7$ & $1.03 \mathrm{e}-7$ \\
\hline 7 & $1.78 \mathrm{e}-6$ & $1.39 \mathrm{e}-6$ & $1.12 \mathrm{e}-6$ & $9.22 \mathrm{e}-7$ & $7.71 \mathrm{e}-7$ & $6.53 \mathrm{e}-7$ \\
\hline 8 & $3.27 \mathrm{e}+0$ & $2.72 \mathrm{e}+0$ & $2.33 \mathrm{e}+0$ & $2.04 \mathrm{e}+0$ & $1.81 \mathrm{e}+0$ & $1.63 \mathrm{e}+0$ \\
\hline 9 & $6.60 \mathrm{e}-7$ & $4.43 \mathrm{e}-7$ & $3.02 \mathrm{e}-7$ & $2.08 \mathrm{e}-7$ & $1.44 \mathrm{e}-7$ & $1.01 \mathrm{e}-7$ \\
\hline 10 & $2.99 \mathrm{e}-5$ & $2.03 \mathrm{e}-5$ & $1.39 \mathrm{e}-5$ & $9.62 \mathrm{e}-6$ & $6.71 \mathrm{e}-6$ & $4.71 \mathrm{e}-6$ \\
\hline 11 & $1.59 \mathrm{e}-6$ & $1.20 \mathrm{e}-6$ & $9.27 \mathrm{e}-7$ & $7.34 \mathrm{e}-7$ & $5.90 \mathrm{e}-7$ & $4.81 \mathrm{e}-7$ \\
\hline 12 & $1.19 \mathrm{e}-6$ & $8.45 \mathrm{e}-7$ & $6.16 \mathrm{e}-7$ & $4.59 \mathrm{e}-7$ & $3.48 \mathrm{e}-7$ & $2.68 \mathrm{e}-7$ \\
\hline 14 & $7.55 \mathrm{e}-7$ & $4.86 \mathrm{e}-7$ & $3.22 \mathrm{e}-7$ & $2.18 \mathrm{e}-7$ & $1.50 \mathrm{e}-7$ & $1.05 \mathrm{e}-7$ \\
\hline
\end{tabular}

\begin{tabular}{|r|c|c|c|c|c|c|}
\hline Case & \multicolumn{6}{|c|}{ Downwind Distance (mi) } \\
\cline { 2 - 7 } & 3.7 & 1.10 & 1.83 & 3.67 & 5.87 & 8.07 \\
\hline 2 & $1.71 \mathrm{e}-4$ & $1.04 \mathrm{e}-4$ & $5.96 \mathrm{e}-5$ & $2.20 \mathrm{e}-5$ & $9.41 \mathrm{e}-6$ & $5.04 \mathrm{e}-6$ \\
\hline
\end{tabular}

\begin{tabular}{|c|c|c|c|c|c|c|}
\hline Case & \multicolumn{6}{|c|}{ Downwind Distance (mi) } \\
\cline { 2 - 7 } & 10.27 & 12.47 & 14.67 & 16.87 & 19.07 & 21.27 \\
\hline 2 & $2.97 \mathrm{e}-6$ & $1.82 \mathrm{e}-6$ & $1.15 \mathrm{e}-6$ & $7.45 \mathrm{e}-7$ & $4.89 \mathrm{e}-7$ & $3.25 \mathrm{e}-7$ \\
\hline
\end{tabular}


Table 11 (cont'd)

Inhalation Dose (rem), "Puff" Calculations:

\begin{tabular}{|r|r|r|r|r|r|r|}
\hline Case & \multicolumn{7}{|c|}{ Downwind Distance (mi) } \\
\cline { 2 - 7 } & 0.37 & 1.12 & 1.87 & 3.73 & 5.97 & 8.21 \\
\hline 1 & $2.04 \mathrm{e}-5$ & $1.19 \mathrm{e}-5$ & $6.67 \mathrm{e}-6$ & $2.60 \mathrm{e}-6$ & $1.28 \mathrm{e}-6$ & $7.69 \mathrm{e}-7$ \\
\hline 3 & $1.03 \mathrm{e}-5$ & $6.06 \mathrm{e}-6$ & $3.42 \mathrm{e}-6$ & $1.37 \mathrm{e}-6$ & $6.95 \mathrm{e}-7$ & $4.30 \mathrm{e}-7$ \\
\hline 4 & $1.41 \mathrm{e}-5$ & $2.37 \mathrm{e}-6$ & $8.89 \mathrm{e}-7$ & $3.82 \mathrm{e}-7$ & $2.26 \mathrm{e}-7$ & $1.55 \mathrm{e}-7$ \\
\hline 5 & $2.70 \mathrm{e}-7$ & $1.29 \mathrm{e}-5$ & $1.87 \mathrm{e}-5$ & $1.40 \mathrm{e}-5$ & $9.46 \mathrm{e}-6$ & $6.83 \mathrm{e}-6$ \\
\hline 6 & $1.41 \mathrm{e}-5$ & $2.37 \mathrm{e}-6$ & $8.89 \mathrm{e}-7$ & $2.20 \mathrm{e}-7$ & $1.14 \mathrm{e}-7$ & $7.83 \mathrm{e}-8$ \\
\hline 7 & $2.04 \mathrm{e}-5$ & $1.19 \mathrm{e}-5$ & $6.67 \mathrm{e}-6$ & $2.60 \mathrm{e}-6$ & $1.28 \mathrm{e}-6$ & $7.69 \mathrm{e}-7$ \\
\hline 8 & $2.86 \mathrm{e}+1$ & $1.71 \mathrm{e}+1$ & $9.74 \mathrm{e}+0$ & $4.00 \mathrm{e}+0$ & $2.09 \mathrm{e}+0$ & $1.33 \mathrm{e}+0$ \\
\hline 9 & $7.05 \mathrm{e}-5$ & $1.10 \mathrm{e}-5$ & $3.83 \mathrm{e}-6$ & $1.32 \mathrm{e}-6$ & $6.14 \mathrm{e}-7$ & $3.31 \mathrm{e}-7$ \\
\hline 10 & $1.18 \mathrm{e}-6$ & $5.54 \mathrm{e}-5$ & $7.78 \mathrm{e}-5$ & $4.83 \mathrm{e}-5$ & $2.56 \mathrm{e}-5$ & $1.45 \mathrm{e}-5$ \\
\hline 11 & $2.06 \mathrm{e}-5$ & $1.20 \mathrm{e}-5$ & $6.71 \mathrm{e}-6$ & $2.58 \mathrm{e}-6$ & $1.24 \mathrm{e}-6$ & $7.16 \mathrm{e}-7$ \\
\hline 12 & $2.04 \mathrm{e}-5$ & $1.17 \mathrm{e}-5$ & $6.39 \mathrm{e}-6$ & $2.33 \mathrm{e}-6$ & $1.05 \mathrm{e}-6$ & $5.71 \mathrm{e}-7$ \\
\hline 14 & $2.01 \mathrm{e}-5$ & $1.12 \mathrm{e}-5$ & $5.89 \mathrm{e}-6$ & $1.98 \mathrm{e}-6$ & $8.06 \mathrm{e}-7$ & $3.98 \mathrm{e}-7$ \\
\hline
\end{tabular}

\begin{tabular}{|r|r|r|r|r|r|r|}
\hline Case & \multicolumn{7}{|c|}{ Downwind Distance (mi) } \\
\cline { 2 - 7 } & 10.45 & 12.69 & 14.93 & 17.17 & 19.41 & 21.65 \\
\hline 1 & $5.13 \mathrm{e}-7$ & $3.65 \mathrm{e}-7$ & $2.80 \mathrm{e}-7$ & $2.30 \mathrm{e}-7$ & $1.93 \mathrm{e}-7$ & $1.63 \mathrm{e}-7$ \\
\hline 3 & $2.95 \mathrm{e}-7$ & $2.16 \mathrm{e}-7$ & $1.71 \mathrm{e}-7$ & $1.45 \mathrm{e}-7$ & $1.25 \mathrm{e}-7$ & $1.09 \mathrm{e}-7$ \\
\hline 4 & $1.15 \mathrm{e}-7$ & $8.92 \mathrm{e}-8$ & $7.38 \mathrm{e}-8$ & $6.48 \mathrm{e}-8$ & $5.74 \mathrm{e}-8$ & $5.11 \mathrm{e}-8$ \\
\hline 5 & $5.18 \mathrm{e}-6$ & $4.08 \mathrm{e}-6$ & $3.40 \mathrm{e}-6$ & $3.00 \mathrm{e}-6$ & $2.67 \mathrm{e}-6$ & $2.38 \mathrm{e}-6$ \\
\hline 6 & $5.80 \mathrm{e}-8$ & $4.50 \mathrm{e}-8$ & $3.72 \mathrm{e}-8$ & $3.27 \mathrm{e}-8$ & $2.89 \mathrm{e}-8$ & $2.58 \mathrm{e}-8$ \\
\hline 7 & $5.13 \mathrm{e}-7$ & $3.65 \mathrm{e}-7$ & $2.80 \mathrm{e}-7$ & $2.30 \mathrm{e}-7$ & $1.93 \mathrm{e}-7$ & $1.63 \mathrm{e}-7$ \\
\hline 8 & $9.45 \mathrm{e}-1$ & $7.14 \mathrm{e}-1$ & $5.82 \mathrm{e}-1$ & $5.09 \mathrm{e}-1$ & $4.53 \mathrm{e}-1$ & $4.07 \mathrm{e}-1$ \\
\hline 9 & $1.92 \mathrm{e}-7$ & $1.17 \mathrm{e}-7$ & $7.54 \mathrm{e}-8$ & $5.19 \mathrm{e}-8$ & $3.61 \mathrm{e}-8$ & $2.53 \mathrm{e}-8$ \\
\hline 10 & $8.66 \mathrm{e}-6$ & $5.35 \mathrm{e}-6$ & $3.48 \mathrm{e}-6$ & $2.41 \mathrm{e}-6$ & $1.68 \mathrm{e}-6$ & $1.18 \mathrm{e}-6$ \\
\hline 11 & $4.59 \mathrm{e}-7$ & $3.14 \mathrm{e}-7$ & $2.32 \mathrm{e}-7$ & $1.83 \mathrm{e}-7$ & $1.48 \mathrm{e}-7$ & $1.20 \mathrm{e}-7$ \\
\hline 12 & $3.44 \mathrm{e}-7$ & $2.22 \mathrm{e}-7$ & $1.54 \mathrm{e}-7$ & $1.15 \mathrm{e}-7$ & $8.71 \mathrm{e}-8$ & $6.69 \mathrm{e}-8$ \\
\hline 14 & $2.18 \mathrm{e}-7$ & $1.27 \mathrm{e}-7$ & $8.05 \mathrm{e}-8$ & $5.45 \mathrm{e}-8$ & $3.76 \mathrm{e}-8$ & $2.63 \mathrm{e}-8$ \\
\hline
\end{tabular}

\begin{tabular}{|r|c|c|c|c|c|c|}
\hline Case & \multicolumn{7}{|c|}{ Downwind Distance (mi) } \\
\cline { 2 - 7 } & 0.37 & 1.10 & 1.83 & 3.67 & 5.87 & 8.07 \\
\hline 2 & $9.92 \mathrm{e}-5$ & $5.48 \mathrm{e}-5$ & $2.84 \mathrm{e}-5$ & $9.07 \mathrm{e}-6$ & $3.51 \mathrm{e}-6$ & $1.65 \mathrm{e}-6$ \\
\hline
\end{tabular}

\begin{tabular}{|r|c|c|c|c|c|c|}
\hline Case & \multicolumn{7}{|c|}{ Downwind Distance (mi) } \\
\cline { 2 - 7 } & 10.27 & 12.47 & 14.67 & 16.87 & 19.07 & 21.27 \\
\hline 2 & $8.65 \mathrm{e}-7$ & $4.83 \mathrm{e}-7$ & $2.88 \mathrm{e}-7$ & $1.86 \mathrm{e}-7$ & $1.22 \mathrm{e}-7$ & $8.13 \mathrm{e}-8$ \\
\hline
\end{tabular}

\begin{tabular}{|r|c|c|c|c|c|c|}
\hline Case & \multicolumn{6}{|c|}{ Downwind Distance (mi) } \\
\cline { 2 - 7 } & 0.67 & 1.33 & 2.00 & 2.67 & 3.33 & 4.00 \\
\hline 15 & $4.94 \mathrm{e}-5$ & $2.61 \mathrm{e}-5$ & $1.55 \mathrm{e}-5$ & $1.03 \mathrm{e}-5$ & $7.29 \mathrm{e}-6$ & $5.43 \mathrm{e}-6$ \\
\hline
\end{tabular}

\begin{tabular}{|r|c|c|c|c|c|c|}
\hline Case & \multicolumn{7}{|c|}{ Downwind Distance (mi) } \\
\cline { 2 - 7 } & 6.33 & 8.67 & 11.00 & 14.33 & 17.67 & 21.00 \\
\hline 15 & $1.48 \mathrm{e}-6$ & $8.59 \mathrm{e}-7$ & $5.52 \mathrm{e}-7$ & $2.41 \mathrm{e}-7$ & $1.78 \mathrm{e}-7$ & $1.36 \mathrm{e}-7$ \\
\hline
\end{tabular}


Table 12. Ground centerline inhalation and cloud shine dose at selected downwind distances predicted by 2DPUF using the input parameters specified in Table 5

Inhalation Dose (rem), "Puff" Calculations:

\begin{tabular}{|r|c|c|c|c|c|c|}
\hline Case & \multicolumn{7}{|c|}{ Downwind Distance (mi) } \\
\cline { 2 - 7 } & 1.0 & 2.0 & 3.0 & 4.0 & 5.0 & 6.0 \\
\hline 1 & $1.36 \mathrm{e}-5$ & $4.16 \mathrm{e}-6$ & $1.89 \mathrm{e}-6$ & $1.06 \mathrm{e}-6$ & $6.73 \mathrm{e}-7$ & $5.27 \mathrm{e}-7$ \\
\hline 2 & $6.03 \mathrm{e}-5$ & $1.69 \mathrm{e}-5$ & $6.92 \mathrm{e}-6$ & $3.46 \mathrm{e}-6$ & $1.97 \mathrm{e}-6$ & $1.38 \mathrm{e}-6$ \\
\hline 3 & $7.54 \mathrm{e}-6$ & $2.16 \mathrm{e}-6$ & $9.83 \mathrm{e}-7$ & $5.58 \mathrm{e}-7$ & $3.61 \mathrm{e}-7$ & $2.86 \mathrm{e}-7$ \\
\hline 4 & $2.95 \mathrm{e}-6$ & $7.75 \mathrm{e}-7$ & $4.63 \mathrm{e}-7$ & $3.37 \mathrm{e}-7$ & $2.62 \mathrm{e}-7$ & $2.14 \mathrm{e}-7$ \\
\hline 5 & $2.88 \mathrm{e}-6$ & $2.23 \mathrm{e}-5$ & $2.14 \mathrm{e}-5$ & $1.65 \mathrm{e}-5$ & $1.21 \mathrm{e}-5$ & $9.09 \mathrm{e}-6$ \\
\hline 6 & $2.95 \mathrm{e}-6$ & $7.61 \mathrm{e}-7$ & $3.33 \mathrm{e}-7$ & $1.86 \mathrm{e}-7$ & $1.33 \mathrm{e}-7$ & $1.08 \mathrm{e}-7$ \\
\hline 7 & $1.36 \mathrm{e}-5$ & $4.16 \mathrm{e}-6$ & $1.89 \mathrm{e}-6$ & $1.06 \mathrm{e}-6$ & $6.67 \mathrm{e}-7$ & $4.53 \mathrm{e}-7$ \\
\hline 8 & $1.93 \mathrm{e}+1$ & $6.09 \mathrm{e}+0$ & $2.85 \mathrm{e}+0$ & $1.64 \mathrm{e}+0$ & $1.07 \mathrm{e}+0$ & $8.61 \mathrm{e}-1$ \\
\hline
\end{tabular}

\begin{tabular}{|r|c|c|c|c|c|c|}
\hline Case & \multicolumn{7}{|c|}{ Downwind Distance (mi) } \\
\cline { 2 - 7 } & \multicolumn{7}{|c|}{7.0} & 8.0 & 9.0 & 10.0 & 12.0 & 14.0 \\
\hline 1 & $4.40 \mathrm{e}-7$ & $3.75 \mathrm{e}-7$ & $3.25 \mathrm{e}-7$ & $2.85 \mathrm{e}-7$ & $2.25 \mathrm{e}-7$ & $1.82 \mathrm{e}-7$ \\
\hline 2 & $1.03 \mathrm{e}-6$ & $7.88 \mathrm{e}-7$ & $6.12 \mathrm{e}-7$ & $4.79 \mathrm{e}-7$ & $3.03 \mathrm{e}-7$ & $1.98 \mathrm{e}-7$ \\
\hline 3 & $2.43 \mathrm{e}-7$ & $2.09 \mathrm{e}-7$ & $1.83 \mathrm{e}-7$ & $1.63 \mathrm{e}-7$ & $1.32 \mathrm{e}-7$ & $1.10 \mathrm{e}-7$ \\
\hline 4 & $1.78 \mathrm{e}-7$ & $1.52 \mathrm{e}-7$ & $1.31 \mathrm{e}-7$ & $1.15 \mathrm{e}-7$ & $9.05 \mathrm{e}-8$ & $7.38 \mathrm{e}-8$ \\
\hline 5 & $6.89 \mathrm{e}-6$ & $5.34 \mathrm{e}-6$ & $4.23 \mathrm{e}-6$ & $3.40 \mathrm{e}-6$ & $2.30 \mathrm{e}-6$ & $1.63 \mathrm{e}-6$ \\
\hline 6 & $8.97 \mathrm{e}-8$ & $7.66 \mathrm{e}-8$ & $6.63 \mathrm{e}-8$ & $5.81 \mathrm{e}-8$ & $4.56 \mathrm{e}-8$ & $3.72 \mathrm{e}-8$ \\
\hline 7 & $3.26 \mathrm{e}-7$ & $2.43 \mathrm{e}-7$ & $1.88 \mathrm{e}-7$ & $1.50 \mathrm{e}-7$ & $1.14 \mathrm{e}-7$ & $9.20 \mathrm{e}-8$ \\
\hline 8 & $7.39 \mathrm{e}-1$ & $6.47 \mathrm{e}-1$ & $5.75 \mathrm{e}-1$ & $5.19 \mathrm{e}-1$ & $4.33 \mathrm{e}-1$ & $3.70 \mathrm{e}-1$ \\
\hline
\end{tabular}

\begin{tabular}{|r|r|r|r|}
\hline Case & \multicolumn{3}{|c|}{ Downind Distance (mi) } \\
\cline { 2 - 4 } & 16.0 & 18.0 & 20.0 \\
\hline 1 & $1.52 \mathrm{e}-7$ & $1.28 \mathrm{e}-7$ & $1.09 \mathrm{e}-7$ \\
\hline 2 & $1.31 \mathrm{e}-7$ & $8.89 \mathrm{e}-8$ & $6.10 \mathrm{e}-8$ \\
\hline 3 & $9.40 \mathrm{e}-8$ & $8.12 \mathrm{e}-8$ & $7.13 \mathrm{e}-8$ \\
\hline 4 & $6.12 \mathrm{e}-8$ & $5.15 \mathrm{e}-8$ & $4.39 \mathrm{e}-8$ \\
\hline 5 & $1.20 \mathrm{e}-6$ & $9.05 \mathrm{e}-7$ & $6.98 \mathrm{e}-7$ \\
\hline 6 & $3.08 \mathrm{e}-8$ & $2.60 \mathrm{e}-8$ & $2.21 \mathrm{e}-8$ \\
\hline 7 & $7.65 \mathrm{e}-8$ & $6.43 \mathrm{e}-8$ & $5.48 \mathrm{e}-8$ \\
\hline 8 & $3.25 \mathrm{e}-1$ & $2.88 \mathrm{e}-1$ & $2.59 \mathrm{e}-1$ \\
\hline
\end{tabular}


Table 12 (cont'd)

Cloud Shine Dose (rem), "Puff" Calculations:

\begin{tabular}{|r|r|r|r|r|r|r|}
\hline Case & \multicolumn{7}{|c|}{ Downwind Distance (mi) } \\
\cline { 2 - 7 } & 1.0 & \multicolumn{1}{|c|}{1.0} & \multicolumn{1}{|c|}{3.0} & 4.0 & \multicolumn{1}{c|}{5.0} & \multicolumn{1}{c|}{6.0} \\
\hline 1 & $4.06 \mathrm{e}-5$ & $1.24 \mathrm{e}-5$ & $5.67 \mathrm{e}-6$ & $3.17 \mathrm{e}-6$ & $2.01 \mathrm{e}-6$ & $1.58 \mathrm{e}-6$ \\
\hline 2 & $1.81 \mathrm{e}-4$ & $5.06 \mathrm{e}-5$ & $2.07 \mathrm{e}-5$ & $1.04 \mathrm{e}-5$ & $5.9 \mathrm{e}-6$ & $4.14 \mathrm{e}-6$ \\
\hline 3 & $2.26 \mathrm{e}-5$ & $6.48 \mathrm{e}-6$ & $2.95 \mathrm{e}-6$ & $1.67 \mathrm{e}-6$ & $1.08 \mathrm{e}-6$ & $8.56 \mathrm{e}-7$ \\
\hline 4 & $8.84 \mathrm{e}-6$ & $2.32 \mathrm{e}-6$ & $1.39 \mathrm{e}-6$ & $1.01 \mathrm{e}-6$ & $7.86 \mathrm{e}-7$ & $6.4 \mathrm{e}-7$ \\
\hline 5 & $8.63 \mathrm{e}-6$ & $6.69 \mathrm{e}-5$ & $6.39 \mathrm{e}-5$ & $4.94 \mathrm{e}-5$ & $3.63 \mathrm{e}-5$ & $2.72 \mathrm{e}-5$ \\
\hline 6 & $8.84 \mathrm{e}-6$ & $2.28 \mathrm{e}-6$ & $9.98 \mathrm{e}-7$ & $5.57 \mathrm{e}-7$ & $3.98 \mathrm{e}-7$ & $3.23 \mathrm{e}-7$ \\
\hline 7 & $4.06 \mathrm{e}-5$ & $1.24 \mathrm{e}-5$ & $5.67 \mathrm{e}-6$ & $3.17 \mathrm{e}-6$ & $2 \mathrm{e}-6$ & $1.36 \mathrm{e}-6$ \\
\hline 8 & $1.55 \mathrm{e}-9$ & $4.87 \mathrm{e}-10$ & $2.28 \mathrm{e}-10$ & $1.31 \mathrm{e}-10$ & $8.55 \mathrm{e}-11$ & $6.88 \mathrm{e}-11$ \\
\hline
\end{tabular}

\begin{tabular}{|r|r|r|r|r|r|r|}
\hline Case & \multicolumn{7}{|c|}{ Downwind Distance (mi) } \\
\cline { 2 - 7 } & \multicolumn{1}{|c|}{7.0} & \multicolumn{1}{|c|}{1.0} & 9.0 & 10.0 & 12.0 & \multicolumn{1}{|c|}{14.0} \\
\hline 1 & $1.32 \mathrm{e}-6$ & $1.12 \mathrm{e}-6$ & $9.72 \mathrm{e}-7$ & $8.54 \mathrm{e}-7$ & $6.75 \mathrm{e}-7$ & $5.46 \mathrm{e}-7$ \\
\hline 2 & $2.36 \mathrm{e}-6$ & $1.83 \mathrm{e}-6$ & $1.43 \mathrm{e}-6$ & $9.06 \mathrm{e}-7$ & $5.92 \mathrm{e}-7$ & $3.09 \mathrm{e}-6$ \\
\hline 3 & $7.26 \mathrm{e}-7$ & $6.25 \mathrm{e}-7$ & $5.49 \mathrm{e}-7$ & $4.88 \mathrm{e}-7$ & $3.96 \mathrm{e}-7$ & $3.3 \mathrm{e}-7$ \\
\hline 4 & $5.32 \mathrm{e}-7$ & $4.55 \mathrm{e}-7$ & $3.94 \mathrm{e}-7$ & $3.45 \mathrm{e}-7$ & $2.71 \mathrm{e}-7$ & $2.21 \mathrm{e}-7$ \\
\hline 5 & $2.06 \mathrm{e}-5$ & $1.60 \mathrm{e}-5$ & $1.27 \mathrm{e}-5$ & $1.02 \mathrm{e}-5$ & $6.9 \mathrm{e}-6$ & $4.89 \mathrm{e}-6$ \\
\hline 6 & $2.69 \mathrm{e}-7$ & $2.29 \mathrm{e}-7$ & $1.99 \mathrm{e}-7$ & $1.74 \mathrm{e}-7$ & $1.37 \mathrm{e}-7$ & $1.11 \mathrm{e}-7$ \\
\hline 7 & $7.29 \mathrm{e}-7$ & $5.62 \mathrm{e}-7$ & $4.48 \mathrm{e}-7$ & $3.40 \mathrm{e}-7$ & $2.76 \mathrm{e}-7$ & $9.76 \mathrm{e}-7$ \\
\hline 8 & $5.91 \mathrm{e}-11$ & $5.17 \mathrm{e}-11$ & $4.6 \mathrm{e}-11$ & $4.15 \mathrm{e}-11$ & $3.46 \mathrm{e}-11$ & $2.96 \mathrm{e}-11$ \\
\hline
\end{tabular}

\begin{tabular}{|r|r|r|r|}
\hline Case & \multicolumn{3}{|c|}{ Downwind Distance (mi) } \\
\cline { 2 - 4 } & 16.0 & 18.0 & \multicolumn{1}{|c|}{20.0} \\
\hline 1 & $4.55 \mathrm{e}-7$ & $3.82 \mathrm{e}-7$ & $3.26 \mathrm{e}-7$ \\
\hline 2 & $3.93 \mathrm{e}-7$ & $2.66 \mathrm{e}-7$ & $1.83 \mathrm{e}-7$ \\
\hline 3 & $2.82 \mathrm{e}-7$ & $2.43 \mathrm{e}-7$ & $2.13 \mathrm{e}-7$ \\
\hline 4 & $1.83 \mathrm{e}-7$ & $1.54 \mathrm{e}-7$ & $1.31 \mathrm{e}-7$ \\
\hline 5 & $3.59 \mathrm{e}-6$ & $2.71 \mathrm{e}-6$ & $2.09 \mathrm{e}-6$ \\
\hline 6 & $9.24 \mathrm{e}-8$ & $7.78 \mathrm{e}-8$ & $6.63 \mathrm{e}-8$ \\
\hline 7 & $2.29 \mathrm{e}-7$ & $1.93 \mathrm{e}-7$ & $1.64 \mathrm{e}-7$ \\
\hline 8 & $2.6 \mathrm{e}-11$ & $2.31 \mathrm{e}-11$ & $2.07 \mathrm{e}-11$ \\
\hline
\end{tabular}



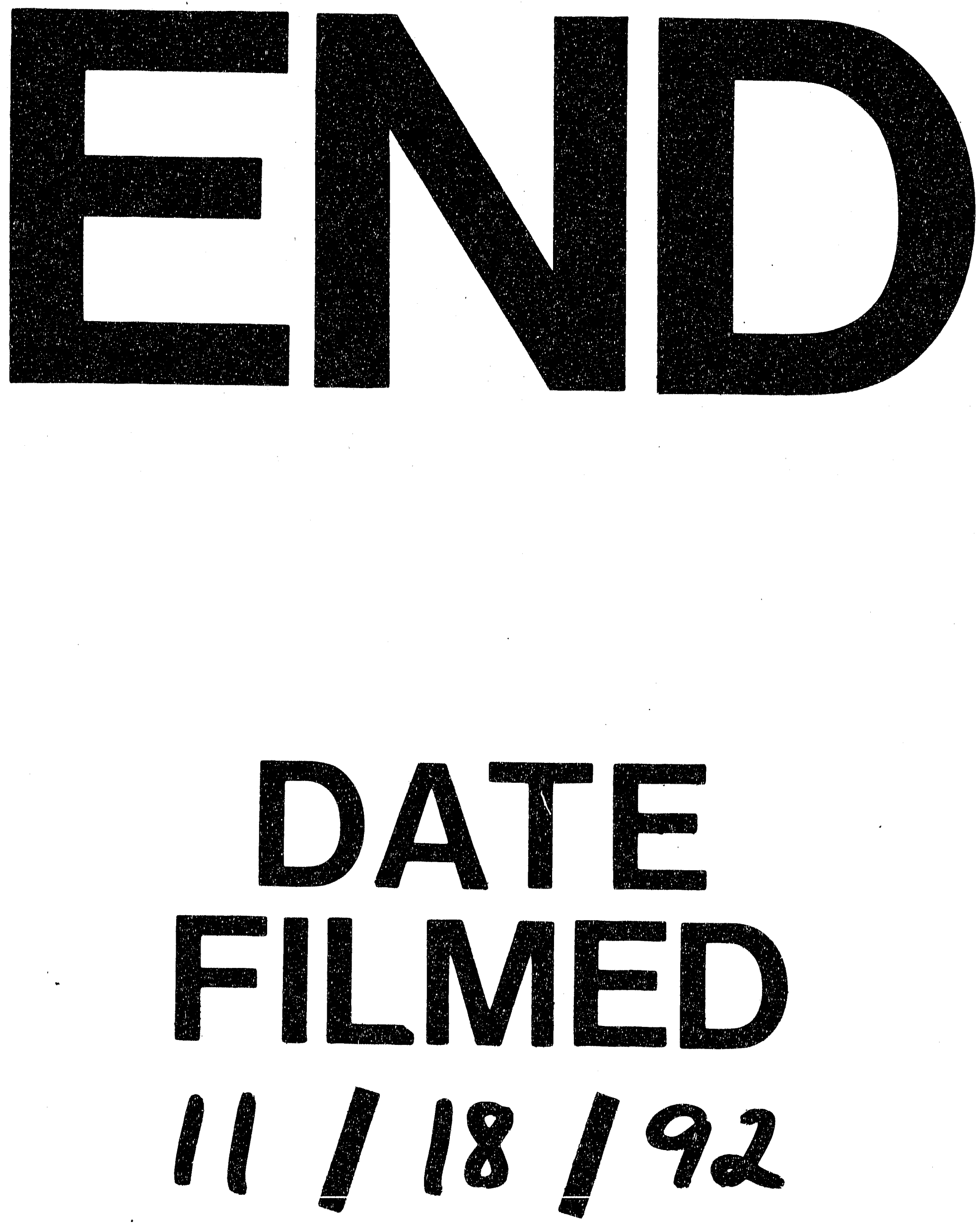


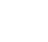

